\title{
Políticas públicas y embarazo adolescente. Un estudio de caso en Caleta Olivia para el ajuste y adecuación de las políticas del Ministerio de Desarrollo Social orientadas a la población adolescente
}

\author{
Public policies and teen pregnancy. A case study in Caleta Olivia for adjusting and \\ adapting the policies of the Ministry of Social Development aimed at the adolescent \\ population \\ Sandra Roldán, Lía Guerra, Agueda Isla, Graciela López \\ sandralilianaroldan@gmail.com,lgguerra@yahoo.com,aguedaisla@hotmail.com, \\ lachaque77@yahoo.com.ar \\ Unidad Académica Caleta Olivia - Universidad Nacional de la Patagonia Austral, Acceso \\ Norte Ruta 3 s/n - Caleta Olivia - Santa Cruz - Argentina
}

Recibido: 29/07/2019. Aceptado: 28/10/2019

\begin{abstract}
RESUMEN
Parte fundamental, y condición inicial, de la solución de un problema es tenerlo claramente identificado. En tal sentido, la provincia de Santa Cruz no cuenta con un sistema estadístico relativo a la niñez y adolescencia, el cual - según declaraciones recientes de funcionarios con competencia en el área - se hallaría en construcción. La ONU ha observado (6/12/16) que en la mayoría de los países no existen datos sistematizados para orientar las políticas, detectar deficiencias y optimizar la asignación de recursos. Argentina, y particularmente la provincia de Santa Cruz no son una excepción. Por ello el objetivo del proyecto se centró en producir conocimiento sobre el estado de situación del embarazo adolescente y las políticas públicas implementadas para su prevención, con objeto de contribuir al mejoramiento de su eficacia, para lo cual se realizó un estudio de tipo exploratorio cuanti-cualitativo. En primer lugar, se procedió a la caracterización de planes y programas nacionales y provinciales, y en segundo lugar el desarrollo de talleres para adolescentes en el CIC, charlas en escuelas, entrevistas a gestoras de políticas públicas y un conversatorio popular. Pese a las cuantiosas inversiones estatales puede observarse que, la tasa de fecundidad adolescente -fuertemente correlacionada con la desigualdad social- no desciende en términos comparativos en la región al mismo tiempo que se presentan yuxtaposiciones, desacoples y desarticulaciones en las políticas públicas, un alto esfuerzo de articulación en territorio que resulta insuficiente, y adolescentes que, pese a la existencia de acciones del estado, no se perciben como destinatarios/as de dichas políticas.
\end{abstract}

Palabras clave: Embarazo adolescente; políticas públicas; desigualdad social.

\begin{abstract}
A fundamental part, and initial condition, of the solution of a problem is to have it clearly identified. In this sense, the province of Santa Cruz does not have a statistical system related to childhood and adolescence, which - according to recent declarations of officials with competence in the area - would be under construction. The UN has observed (6/12/16) that in most countries there are no systematized data to guide policies, detect deficiencies and optimize the allocation of resources. Argentina, and particularly the province of Santa Cruz
\end{abstract}


are not an exception. For this reason, the objective of the project was focused on producing knowledge on the status of adolescent pregnancy and the public policies implemented for its prevention, in order to contribute to the improvement of its effectiveness, for which a quanti - qualitative exploratory study was carried out. In the first place, the characterization of national and provincial plans and programs was carried out, followed by the development of workshops for adolescents in the CIC, talks in schools, interviews with public policy makers and a popular conversation. Despite the large state investments, it can be observed that the adolescent fertility rate -strongly correlated with social inequality- does not decrease in comparative terms in the region at the same time as juxtapositions, uncoupling and disarticulations in public policies are presented, a high articulation effort in territory that is insufficient, and adolescents who, despite the existence of actions of the state, are not perceived as recipients of such policies.

Key words: Teen pregnancy; public politics; Social inequality.

\section{INTRODUCCIÓN}

El proyecto de investigación, de tipo exploratorio y de un año de duración, se enmarca en el Programa de Políticas Públicas Sociales creado en la UNPA a mediados del 2018, a efecto de la creación de líneas y grupos de investigación en políticas públicas sociales en el ámbito de la institución, con el propósito de identificar problemáticas que requieran abordaje investigativo y la producción de conocimiento para contribuir a la implementación, generación y formulación de propuestas superadoras de las actuales. El mismo fue declarado de interés provincial por el Poder Legislativo de la provincia de santa Cruz (Resolución 254/18, del 17 de Diciembre de 2018).

En este marco y a partir de demandas de actoras/gestoras públicas del CIC Virgen del Valle de la ciudad de Caleta Olivia -que se incorporaron como integrantes al equipo de investigación constituido a partir de la convocatoria - emergen como tema relevante las formas de abordaje y comprensión del fenómeno de la maternidad adolescente en los casos que interviene el CIC, esto, es decir, en la población en situación de desigualdad social.

Indudablemente lo local debe leerse asimismo en clave global considerando que la temática ha sido objeto de acuerdos políticos regionales en América Latina que indican a las claras la relevancia del fenómeno. Según un estudio de UNICEF (2017), Argentina presenta la mayor tasa de maternidad adolescente (considerando mujeres de entre 15 y 20 años de edad) de Latinoamérica, y en ese marco el $15 \%$ de los nacimientos en país corresponden a madres adolescentes, dato que se mantiene estable desde los últimos 25 años. Datos oficiales dan cuenta de que de manera sostenida alrededor de 3.000 nacimientos al año corresponden a madres menores de 15 años, y es un hecho reconocido que a menor edad de la madre mayores son los riesgos para su salud y la de sus hijos/as. Mención especial requiere el hecho de que con frecuencia los embarazos en este último grupo involucran situaciones de abuso sexual.

Informes del Ministerio de Salud de la Nación reportan que, en la adolescencia, 6 de cada 10 embarazos no son planificados, y los métodos anticonceptivos no son accesibles gratuitamente para 6 de cada 10 mujeres y 7 de cada 10 varones adolescentes (además del hecho de que la distribución de los mismos no garantiza su adecuado u oportuno uso). El $20 \%$ de los nacimientos de madres adolescentes es de madres que han tenido previamente un primer hijo/a. Casi la mitad de las adolescentes madres se encuentran fuera del sistema educativo al momento de embarazarse y 1 de cada 4 madres adolescentes no logra completar la escuela primaria. 
El multidimensional fenómeno del embarazo adolescente no intencional presenta así mayor incidencia en los sectores sociales más vulnerables, correlacionándose con la condición socioeconómica y nivel de estudios, así como con el abandono escolar y la inserción precoz (y en condiciones de precariedad) en el mercado de trabajo, constituyéndose en un evidente factor de reproducción de la desigualdad social.

En Santa Cruz, según datos oficiales, para el año 2015, de un total de 6336 nacidos vivos, 846 madres (poco más del 13\%) tenían menos de 20 años. Y si bien, la provincia ha adherido a la Ley nacional 26.150 (Programa Nacional de Educación Sexual Integral) y a la que establece la creación del Programa Nacional de Salud Sexual y Procreación Responsable (Ley Nacional 25.673), y según autoridades del Estado provincial se trabaja para prevenir embarazos no planificados y se brindan las herramientas necesarias para el cuidado y la prevención, las políticas públicas parecieran - a la luz de los números - no ser suficientes y/o adecuadas.

Parte fundamental, y condición inicial, de la solución de un problema es tenerlo claramente identificado. En tal sentido, la provincia no cuenta con un sistema estadístico relativo a la niñez y adolescencia, el cual - según declaraciones recientes de funcionarios con competencia en el área - se hallaría en construcción. El Comité de los Derechos del Niño de la ONU ha observado (6/12/16) sobre la implementación de los derechos del niño durante la adolescencia, que en la mayoría de los países no existen datos desglosados por edad, sexo, quintil de ingresos, lugar de residencia, condición étnica y discapacidad para orientar las políticas, detectar deficiencias y optimizar la asignación de recursos. Argentina, y particularmente la provincia de Santa Cruz no son una excepción.

Se diseña entonces el proyecto de investigación con el objetivo de producir conocimiento sobre el estado de situación del embarazo adolescente y las políticas públicas implementadas en Caleta Olivia para su prevención, con objeto de contribuir al mejoramiento de su eficacia. Como contribución específica del proceso de investigación se contempló en el diseño la generación de resultados en torno a distintos niveles: A nivel UNPA-UACO: Contar con un Informe final que dé cuenta de la construcción colectiva de conocimiento situado respecto de la temática en cuestión para la generación de líneas de investigación en nuestra universidad. Como resultado parcial se elaboró un documento que fue presentado en el V Encuentro de investigadores, becarios y tesistas de la Patagonia Austral (Río Gallegos, octubre - 2018). A nivel Centro Integral Comunitario - Ministerio de Desarrollo Social: instancias de socialización y retroalimentación con el propósito de que el conocimiento construido contribuyera a una mejor comprensión del fenómeno objeto de estudio para la generación, formulación e implementación de propuestas de intervención y políticas públicas superadoras de las actuales. Respecto de las Operadoras: su participación tuvo como objeto propiciar la reflexión sobre la propia práctica y la construcción de mejores herramientas para el desempeño de su función. Respecto de las/los jóvenes participantes: su inclusión en la experiencia tendió a propiciar el logro de una mayor autonomía en el cuidado de su salud sexual y reproductiva, que promoviera el empoderamiento colectivo para el ejercicio pleno de la ciudadanía.

A partir de lo realizado en el año de investigación y según actividades y estudios llevados a cabo el presente informa se organiza en cinco apartados. En el primero se presenta el contexto conceptual en torno a la temática, en el segundo se describe el enfoque metodológico y las técnicas y fuentes empleadas para la construcción de los datos. Un tercer apartado se ocupa del contexto jurídico - legal y en el cuarto se presenta la construcción y análisis de los datos generados en relación a la maternidad adolescente, a los planes y programas enmarcados en las políticas públicas incluyendo algunos presupuestos asignados y los datos relativos a la perspectiva de los/as actores. Y por último un apartado en donde se plantean algunos debates en torno a los resultados y a posibles temas de relevancia que 
requieren de investigaciones más exhaustivas con la intención de continuar contribuyendo a quienes diseñan e implementan las políticas públicas, especialmente en la provincia de Santa Cruz y Caleta Olivia.

\section{EL CONTEXTO CONCEPTUAL EN TORNO AL EMBARAZO ADOLESCENTE. UNA LECTURA POLÍTICA POSIBLE.}

Según la CEPAL (2017), tener un hijo o hija durante la adolescencia entraña desventajas en las sociedades modernas, y parece definitivamente fuera de lugar en las sociedades post modernas, por razones bien documentadas. Se caracteriza allí a las sociedades modernas (entre las cuales se incluyen todos los países de América Latina), como aquellas cuyos atributos destacados serían el estar basadas en la educación hasta la juventud o incluso más allá, la localización y el trabajo urbanos, la participación femenina en el mercado de trabajo y la existencia de transiciones a la edad adulta según hitos de desempeño diferentes a la reproducción (Billari y Liefbroer, 2010, Grant y Furstenberg 2007; Breibauer y Maddaleno, 2005; Dulanto, 2000). Por otra parte, en las sociedades postmodernas se combinan dichos atributos con "un conjunto de valores denominados postindustriales como: autorrealización, libertad personal, autodeterminación de estilo de vida y relaciones personales, bienestar y calidad de vida valorados por encima de los bienes materiales, cuestionamiento de metanarrativas y de la autoridad tradicional, tolerancia y apoyo a la diversidad (Bachrach, 2001). Frente a los discursos hegemónicos que subrayan la preponderancia de las características posmodernas resulta pertinente considerar que toda sociedad concreta involucra una particular combinación y transición de características modernas y posmodernas, habida cuenta del lugar que ocupa nuestro país y continente en el desarrollo del capitalismo avanzado y de la acumulación de capital internacional.

En América Latina y el Caribe, las anteriores desventajas adquieren una connotación especial, pues está bien documentando que la región es una "anomalía" a escala mundial en términos de nivel, tendencia y desigualdad de la fecundidad adolescente (Rodríguez, 2016, 2014a y 2014b). En efecto, la fecundidad adolescente de América Latina y el Caribe es mayor que la esperada en relación a sus niveles bajos de fecundidad total, su condición de región de ingresos medios y sus índices intermedios o incluso altos de desarrollo humano, urbanización, enrolamiento femenino en el sistema escolar y participación femenina en el trabajo remunerado y en el ámbito público. Adicionalmente, la fecundidad adolescente es extremadamente desigual entre grupos socioeconómicos y las adolescentes pobres registran niveles de fecundidad muy elevados, similares a los de sus contrapartes africanas (Rodríguez, 2016 y 2014b).

Se desagregan a continuación, algunas de dichas "desventajas" que la CEPAL destaca, respecto de las que existe acuerdo tanto en los estudios empíricos como en los documentos de los organismos oficiales:

- el embarazo, parto y puerperio antes de los 20 años implica mayores riesgos de salud para madres y bebés; riesgos que se incrementan significativamente conforme desciende la edad de las madres.

- la maternidad y paternidad tempranas ponen en riesgo la inserción y/o el logro escolar, asociándose asimismo a la incorporación precaria en el mercado de trabajo, en la medida en que requiere asumir los costos económicos de la crianza.

- las madres adolescentes tienen más probabilidades de sufrir sesgos y discriminación de género, experimentar estigma cultural o permanecer atadas a roles femeninos tradicionales. 
- los y las adolescentes son, en principio, menos "maduros/as", en función de lo cual cuentan con menos recursos y capacidades para enfrentar los desafíos que implica la crianza.

- los y las adolescentes que han tenido hijos tienen más dificultades para consolidar una familia.

- la probabilidad de tener hijos en la adolescencia es mucho mayor entre los grupos pobres.

- la combinación de estas desventajas y el sesgo de género (notorio en el hecho de que normalmente son las adolescentes y sus familias las que asumen la mayor parte de las responsabilidades de la crianza) provocan que la fecundidad adolescente sea uno de los componentes del ciclo de reproducción intergeneracional de la pobreza, así como de las desigualdades de género.

- las y los adolescentes tienden a ser más vulnerables a la violencia, a la coerción o la influencia de otros.

- la tolerancia y aceptación familiar y comunitaria hacia la actividad sexual premarital es un asunto sensible; siendo aún en muchos países del mundo en desarrollo las madres adolescentes solteras objeto de estigma y desaprobación, que en algunos casos con lleva castigos formales o informales.

Es en función de dichas adversidades que la fecundidad adolescente es una prioridad para la investigación y la acción en América Latina y el Caribe, especialmente dada su resistencia a la baja sostenida en la región. Entre otros aspectos a considerar respecto de esa resistencia, se ha documentado ampliamente - en las últimas dos décadas - que las políticas de salud sexual y reproductiva que han probado ser exitosas para la población adulta y joven no han mostrado los mismos logros en el caso de las adolescentes (Cherry y Dillon, 2014; UNFPA, 2013; Azevedo y otros, 2012; Bozón, Gayet y Barrientos, 2009; Hoffman y Maynard, 2008; Rodríguez, 2009; Bearinger y otros, 2007; Hopenhayn y Rodríguez, 2007; Breinbauer y Maddaleno, 2005; Flórez y Núñez, 2003; Dulanto, 2000; Bongaarts y Cohen, 1998; Buvinic, 1998).

No obstante, la evidencia a favor de las desventajas implicadas en la maternidad adolescente, se verifica un debate en el campo académico en torno a su existencia y, en consecuencia, a la necesidad de intervenir sobre el fenómeno, dado que algunos investigadores/as consideran que esta fecundidad es más bien racional y deseada, particularmente entre los grupos de menores ingresos. Ello en el marco del debate teórico vigente sobre la evolución de las preferencias reproductivas, la relación de esas preferencias con la edad y la conexión entre dichos factores y el nivel socioeconómico.

En torno al debate conceptual sobre la "deseabilidad" / intencionalidad de la fecundidad adolescente, Rodríguez Vignoli (2017) analiza dos hipótesis: i) la de la "funcionalidad" de la misma entre adolescentes pobres, según la cual existe una importante desigualdad socioeconómica en la deseabilidad (o planificación) de los embarazos entre adolescentes verificándose altos niveles de deseabilidad de nacimientos / embarazos entre adolescentes pobres; ii) la hipótesis de la no deseabilidad general de los nacimientos / embarazos entre las adolescentes, que prioriza las desigualdades de la conducta reproductiva por sobre las desigualdades sociales de la deseabilidad del embarazo, en función de lo cual las barreras al acceso a la anticoncepción serían la principal causa de las actuales desigualdades sociales de la fecundidad adolescente, (con un acceso mucho menor en el caso de adolescentes de bajos ingresos). En este contexto, resulta sumamente relevante el análisis y la discusión teórica sobre la validez conceptual y operativa de las categorías de preferencias, deseos y expectativas reproductivas. Queda claro también que la toma de posición respecto de una u otra de las hipótesis consideradas determinará tanto el diagnóstico del fenómeno como los modos de intervención sobre él en el campo de las políticas públicas, 
hecho que torna imperativa la elucidación de los supuestos subyacentes a ellas, dada la posibilidad de que su efecto sea el contrario al deseado, es decir que reproduzca el hecho social que pretende erradicar.

En relación a las preferencias sexuales y reproductivas de los "sectores vulnerables" , un estudio realizado en nuestro país (Binstock y Gogna, 2015) examina, en base a una encuesta realizada a 1571 mujeres jóvenes y adolescentes, el calendario y el contexto en el que ocurre la iniciación sexual en las capitales de las provincias de Chaco, Misiones y Santiago del Estero y en el área metropolitana de Buenos Aires, obedeciendo la selección de esas regiones a las altas tasas de fecundidad adolescente y, en el caso de las provincias norteñas a que son las que presentan la mayor proporción de jóvenes entre 15 y 19 años que han tenido más de un hijo. En ese marco, se atiende a las potenciales diferencias generacionales entre adolescentes y jóvenes (de entre 20 y 24 años), dado que los/las primeros habrían atravesado la adolescencia "en un contexto normativo y programático más favorable al ejercicio de los derechos sexuales y reproductivos que sus antecesoras" (pág. 115), en referencia a la puesta en vigencia del Programa de Educación Sexual Integral (2006) y la consolidación del Programa Nacional de Salud Sexual y Procreación Responsable (2003) que habrían conllevado un mayor acceso a información y a métodos anticonceptivos.

La iniciación sexual constituye para las autoras "uno de los determinantes próximos más relevantes en el estudio de la fecundidad, y particularmente de la maternidad en la adolescencia", (p. 116) remitiendo a otros estudios (Varela Petito \& Fostik, 2011; Oliveira \& Melo Vieira, 2010; Solís, Gayet \& Juárez, 2008; Binstock \& Näslund-Hadley, 2010) según los cuales "cuanto más temprana la iniciación sexual, mayor el riesgo potencial de un embarazo a edad precoz". En ese contexto, la literatura da cuenta de que la educación es uno de los principales factores asociados a la edad en que ocurre la iniciación sexual. Estudios internacionales tanto de orden cuantitativo como cualitativo, han destacado la relación entre la acumulación de capital educativo y un inicio sexual más tardío (CampoArias et al., 2004; Welti, 2005; Binstock \& Näslund-Hadley 2010; Heilborn et al., 2002; Varela Petito \& Fostik, 2011, Singh \& Wulf, 1998; Mendes Tavares et al., 2009). También resultan significativas las características de la trayectoria educativa; así, Chagas de Almeida (2008) muestra que "los adolescentes con trayectorias irregulares adelantan su debut sexual." (citado en Binstock, pág. 116 ) . Asimismo, Binstock (2015) estima que asistir a la escuela retrasa las chances del debut sexual en un $36 \%$, tornando evidente la relevancia de la permanencia en el sistema educativo para los comportamientos vinculados a la salud sexual y reproductiva, sobre todo en función de análisis complementarios que indican que la asistencia escolar retrasa especialmente la iniciación sexual sin protección.

Respecto del uso de métodos o prácticas para prevenir el embarazo, investigaciones previas indican una mayor frecuencia de uso conforme aumenta la edad de iniciación y la condición social (Ferreira Borges, Teixeira et al, 2006; CEPEP, 2005). El diálogo sobre métodos anticonceptivos con sus parejas previo a la iniciación también se correlaciona con el uso de preservativo en mayor proporción (Reis Brandão \& Heilborn, 2006). Respecto de la relación entre iniciación sexual y nivel socioeconómico, algunos estudios pioneros mostraron que la iniciación sexual era algo más temprana en la clase baja que en la clase media (Pantelides, Geldstein \& Infesta Domínguez, 1995) y que, entre los adolescentes escolarizados de la CABA, era más frecuente entre quienes concurrían a escuelas públicas (Schufer \& Necchi, 1997).

Por otra parte, tratándose de un fenómeno multidimensional, la relevancia de los análisis multivariados se torna notable si consideramos que existe evidencia de que educación y pobreza tienen efectos independientes sobre la probabilidad de usar un método anticonceptivo. En tal sentido, el estudio de Gogna, Fernández \& Zamberlin, (2005) concluyó que en todos los niveles educativos, las jóvenes que vivían en condiciones 
materiales menos precarias tenían más probabilidades de haber usado un anticonceptivo en la iniciación sexual que sus pares de hogares más carenciados.

Se ha estudiado, asimismo, la participación en la iniciación sexual del contexto de crianza, concluyendo que en las adolescentes criadas en el seno de familias monoparentales se adelanta el inicio de la actividad sexual, mientras que el mayor nivel de instrucción materna y mayor adhesión familiar a creencias religiosas intervienen retrasando el debut sexual. Las adolescentes que se criaron en hogares caracterizados por una buena relación familiar y buenos tratos se inician sexualmente más tarde que aquellas que lo hicieron en hogares más conflictivos, en que discusiones y peleas eran frecuentes. También Graaf et al. (2011) señalan que el control y la cohesión familiar, retrasan la iniciación sexual. Las adolescentes cuyas madres tuvieron su primer hijo a los 17 años o menos), así como quienes tuvieron alta paridad (al menos 4 hijos), y tuvieron sus hijos con dos parejas o más, se inician sexualmente significativamente más temprano (comparado con las adolescentes cuyas madres tuvieron su primer hijo a partir de los 18 años, tuvieron un máximo de 3 hijos, y de la misma pareja). No obstante, la observación simultánea de esos indicadores da cuenta de que tanto la paridad total como la edad de la madre al momento de nacer su primer hijo disminuyen su poder asociativo y de significancia estadística, mientras que la cantidad de parejas con que la madre tuvo hijos permanece positiva y significativa. También el grado de supervisión familiar opera como un factor que condiciona la iniciación sexual (cuanto menor el control parental más tempranamente ocurre el debut sexual). Y los resultados son contundentes en cuanto a la importancia de la edad a la que las adolescentes comienzan a salir (cuanto más joven, más tempranamente se inicia sexualmente). Respecto del contexto, la mayoría de las adolescentes $(80 \%)$ se inicia sexualmente con quienes ellas definen como novio, siendo la iniciación sexual matrimonial, o en el marco de una convivencia, prácticamente inexistente.

Otros factores considerados a título de "variables", relativas tanto a la iniciación sexual como a la prevención del embarazo, son la imprevisibilidad de la relación sexual, que sería el principal argumento empleado por las jóvenes que no utilizaron un método anticonceptivo en su iniciación (Gogna, Fernández \& Zamberlin, 2005; Binstock \& Gogna, 2014); la clase social y el sexo respecto del uso de anticonceptivos, verificando que los/as jóvenes de sectores populares y las mujeres se encuentran en una situación de mayor vulnerabilidad al embarazo (Pantelides \& Cerrutti, 1994; Pantelides,2004; Kornblit y Mendes Diz, 1994). En un estudio de Geldstein \& Pantelides (2001) se informa que al momento de la iniciación sexual se habían cuidado sólo el $50 \%$ de las entrevistadas de clase baja, mientras que el porcentaje alcanzaba el $80 \%$ para las de jóvenes de clase media. Pese a ello, es de destacar que la absoluta mayoría de las adolescentes conoce algún método anticonceptivo, registrándose los niveles más bajos (que rondan el 95\%) entre las más jóvenes (10 a 14 años), las menos educadas y las más pobres (Pantelides, Binstock \& Mario, 2007). En este contexto, resulta relevante (dado que buena parte - si no la mayoría - de las políticas públicas giran en torno a la educación sexual) señalar que alrededor del $62 \%$ de las jóvenes indicaron haber tenido alguna charla / clase sobre educación sexual en la escuela, pero alrededor de un $20 \%$ expresó que dicha clase fue tardía, dada su ocurrencia a posteriori de su iniciación sexual. La mayoría de las mujeres declaran haber utilizado algún método anticonceptivo en su debut sexual, proporción que se incrementa sostenidamente según la edad de las mujeres (las generaciones más jóvenes utilizan con mayor frecuencia algún tipo de protección al momento del debut sexual). No obstante, entre un tercio y un cuarto de las adolescentes no realiza ningún tipo de prevención, reportando como motivo principal que lo imprevisto de la situación impidió planificar algún tipo de cuidado, argumento que se reitera en estudios llevados a cabo 10 años atrás. Ello indica a las claras la existencia de una brecha entre "conocimiento" y "práctica", es decir entre conocer los métodos anticonceptivos y 
utilizarlos, lo cual pone en cuestión el presupuesto de la falta de información operante tanto en el diseño como en la ejecución de las políticas públicas.

No obstante, la documentada relación entre las variables relativas a la iniciación sexual y la posibilidad del embarazo adolescente, se carece aún de un estudio comprensivo a nivel nacional, así como de estudios de carácter longitudinal. La necesidad de esos diseños para el estudio tanto de la "motivación" para tener - o no - hijos, como del uso de anticonceptivos (definidas como metas de investigación prioritarias) fue indicada ya por la CEPAL en 1982. Habiendo transcurrido casi cuatro décadas, el desafío continúa vigente.

\section{MATERIALES Y MÉTODOS PARA UNA APROXIMACIÓN AL FENÓMENO}

El estudio realizado se enmarca en los de carácter exploratorio cuanti-cuali (R. Hernández Sampieri, C. Fernández Collado y P. Baptista Lucio, 2006), también denominados "mixtos", por cuanto permiten una mejor comprensión de los fenómenos complejos como el que nos ocupa. En la medida en que se trató de un primer acercamiento a la problemática, dado en función de los parámetros de la convocatoria institucional que previó que la investigación se acotara a un período de un año, se consideró esencial incorporar la perspectiva de los/as actores involucrados al tiempo que se recopilaban y/o construían los datos estadísticos relativos a la incidencia del embarazo adolescente en la región, para lo cual se optó por combinar estrategias y técnicas cuantitativas y cualitativas. El sondeo realizado previamente para la formulación del proyecto dio cuenta de la inexistencia de un política específica (diferenciada para la población adolescente) a nivel provincial, razón por la cual, y en sintonía con la elección del tipo de estudio, se definió también el trabajo con muestra de casos -en esta oportunidad las políticas implementadas a través del Centro Integral Comunitario (CIC) Virgen del Valle de la localidad de Caleta Olivia - priorizando la profundidad y calidad de la información por sobre la cantidad y la estandarización, aun cuando se construyeron datos cuantitativos dado que - como se ha señalado - asumimos que la multidimensionalidad del objeto de estudio requería el cruce de ambos enfoques metodológicos.

Si bien existe literatura disponible respecto a la temática del embarazo adolescente (UNESCO, 2017; Quintero Rondón, Angy Paola, Rojas Betancur, Héctor Mauricio, 2015, Febrero-Mayo; Perrotta, 2006; Climent, 2009), el propósito de este estudio fue la construcción de conocimiento situado que posibilite, por un lado, aportar a una mayor adecuación de las políticas públicas respecto de la temática del embarazo adolescente y por otro, identificar conceptos, situaciones de estudio, variables promisorias o potenciales relaciones entre variables, establecer prioridades o líneas para investigaciones futuras en nuestra universidad.

Partiendo de la no existencia de un programa específico se decidió en una primera instancia relevar y sistematizar la información disponible en el CIC para delimitar la población adolescente que estuviera siendo destinataria o beneficiaria de algunas de las acciones que se vienen desarrollando. De aquí que pretendimos, por un lado, sistematizar la información actualmente disponible en el CIC Virgen del Valle del Plan nacer y Plan carnet de salud de la mujer -según sondeo realizado previamente- y el relevamiento del conjunto de planes o programas que estuvieran en marcha tanto a nivel nacional como provincial. Al delimitar la población destinataria se pretendía construir el perfil sociodemográfico del tema en cuestión razón por la cual se previó la construcción de una base de datos a complementar con la información relevada a través de la implementación de los conversatorios populares.

Los conversatorios populares resultan, desde nuestra perspectiva y opción política, un recurso metodológico valioso en tanto permite acceder a información sobre situaciones, 
aspectos o perspectivas no contempladas en las políticas públicas. No se trata de "recuperar la voz del actor" para oficiar de "traductoras" sino para la generación de instancias colectivas organizadas que al calificar la demanda (por la riqueza colectiva en la reflexión del tema) puedan traducirse en acciones y estrategias para la adecuación de las políticas públicas toda vez que asumimos que la participación en las políticas públicas es una forma de ejercicio de ciudadanía (Villarreal, 2009). De aquí que se planificara una instancia de conversatorio de socialización y retroalimentación destinada al tratamiento colectivo y puesta a consideración de los documentos y datos construidos en este estudio exploratorio.

Por tratarse de políticas públicas se consideró esencial la realización de entrevistas tanto a la Directora del CIC como a las operadoras que intervienen en la implementación de planes y programas en tanto su cotidianeidad les provee de información que no siempre está sistematizada al mismo tiempo que da cuenta de la forma en que se produce la interacción entre operadoras y destinatarias según las representaciones que se jueguen respecto de la temática y que puede constituirse tanto en facilitadores como obstaculizadores de las acciones.

La construcción de este estado de situación respecto de la temática en cuestión se articuló con las tareas de "divulgación" y socialización previstas ya desde la convocatoria institucional que prescribía la presentación de trabajos (que harían las veces de informe de

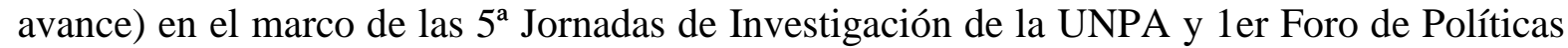
Públicas Sociales, para lo cual fue necesario la elaboración de un artículo a sólo dos meses de iniciado el estudio. El intercambio entre investigadores resultó valioso, pero a efecto de la investigación interesó sobre todo la puesta en conocimiento y discusión a través de una jornada en la localidad con la organización de un Conversatorio popular y paneles donde producir un encuentro de todos lxs actores intervinientes en este proyecto para dar cuenta de la temática y de la experiencia de construcción de este tipo de estudio y de las instancias, formas y sentido de la investigación en la universidad pública.

Los datos cuantitativos relevados tuvieron como fuente los boletines de la Dirección de Estadísticas e Información de Salud (DEIS) elaborados por el Ministerio de Salud y Desarrollo Social de la Nación (Estadísticas vitales e Información Básica e Indicadores seleccionados de salud para población de 10 a 19 años, entre otros), así como también fueron consultadas las estadísticas del Banco Mundial (que cabe mencionar que, llamativamente, cuenta con datos más actualizados que los publicados por las dependencias ministeriales de nuestro país) y las bases de datos de la Comisión Económica para América Latina y el Caribe (CEPAL) de la Organización de Naciones Unidas. Resultó llamativa la discrepancia de datos entre ambas instituciones internacionales lo que derivó en la decisión de trabajar con los datos de las fuentes oficiales de nuestro país para la elaboración de las series evolutivas de la tasa de fecundidad adolescente en el período 1990 - 2016. A este respecto corresponde señalar que si bien el fenómeno que nos propusimos "medir" fue el embarazo adolescente, los datos disponibles sólo permiten identificar la tasa de fecundidad adolescente y no la razón de embarazo adolescente, indicadores claramente diferentes por cuanto resulta obvio que muchos embarazos no llegan a término; pero las estadísticas generadas por el Sistema Estadístico Nacional sólo proveen información en función de la relación entre "nacidos vivos" (además, registrados) y población femenina de un grupo de edad en una zona geográfica dada (tasa específica de fecundidad según edad), a partir de la cual se elabora la tasa de fecundidad adolescente tomando en consideración la población femenina de 10 a 19 años.

Otras fuentes documentales que formaron parte del relevamiento y análisis fueron la legislación nacional y provincial de aplicación en la temática, los programas y planes provinciales y nacionales en implementación en la localidad, planillas y la cartelería, folletería y material de difusión sobre salud sexual y reproductiva disponible en el CIC. Si 
bien en el diseño del proyecto se previó la construcción del perfil sociodemográfico a partir de fuente de datos como las planillas y legajos de las destinatarias de los servicios enmarcados en las políticas públicas que se implementan desde el CIC, ello no fue posible dado los conflictos que atravesó la institución con la comunidad (ataque al CIC por parte de un individuo con antecedentes delictivos y posterior toma de la institución por parte de beneficiarios de planes o beneficios sociales) y los cambios intempestivos de gestión política, ante lo cual se optó por la realización de conversatorios populares abiertos a la ciudad y ampliando la convocatoria a otros actores locales.

En cuanto a las instancias de entrevistas planificadas, conforme a lo previsto en el diseño del proyecto, se administraron entrevistas abiertas $y$ en profundidad y entrevistas semiestructuradas a la Directora del CIC "Virgen del Valle", a la asistente social de la misma institución y a agentes sanitarios que revisten en los centros comunitarios e intervienen en los casos objeto de estudio. Asimismo, se desarrollaron instancias de talleres con adolescentes en el CIC, charlas en instituciones educativas de nivel medio y asociaciones civiles dedicadas al trabajo educativo y recreativo con adolescentes y jóvenes en situación de pobreza. La situación de las madres adolescentes fue abordada en la instancia de conversatorio que tuviera lugar en el marco de la Jornada "Juventudes, desigualdad social y políticas públicas", en la que se contó con la participación de equipos de investigación y referentes académicos en el campo de estudio y de organizaciones civiles de la región patagónica. Ello resultó una instancia no sólo de difusión y divulgación sino fundamentalmente de revisión del saber construido en el marco del proceso de investigación, a partir de la multiplicidad de miradas y voces puestas en diálogo, constituyendo por tanto una opción metodológica.

\section{EL CONTEXTO JURÍDICO EN ARGENTINA Y EN LA PROVINCIA DE SANTA CRUZ}

En nuestro país, las regulaciones relativas a la salud sexual y la procreación, se establecen a partir de la sanción de la Ley 25.673 (promulgada el 21/11/02 y reglamentada por Decreto 1282/2003), por la que se crea, en el ámbito del Ministerio de Salud, el Programa Nacional de Salud Sexual y Procreación Responsable (PNSSyR). Ley que tiene su base en la Constitución Nacional y Tratados Internacionales de DDHH (art.75 inc $22 \mathrm{CN}$ ) y la Convención de los derechos del niño, niña y adolescentes del año 1989 (ratificada por Ley $\left.\mathrm{N}^{\mathrm{o}} 23.849 / 90\right)$ y se articula con el Código penal art. 86 (1921).

Dicho Programa tiene como objetivo alcanzar para la población el nivel más elevado de salud sexual y procreación responsable con el fin de que pueda adoptar decisiones libres de discriminación, coacciones o violencia, para lo cual se propone disminuir la morbimortalidad materno-infantil; prevenir embarazos no deseados; promover la salud sexual de los adolescentes, contribuir a la prevención y detección precoz de enfermedades de transmisión sexual, de VIH/sida y patologías genital y mamarias; garantizar a toda la población el acceso a la información, orientación, métodos y prestaciones de servicios referidos a la salud sexual y procreación responsable y potenciar la participación femenina en la toma de decisiones relativas a su salud sexual y procreación responsable.

Dicha Ley tuvo por efecto que se incluyan en el Programa Médico Obligatorio (PMO) las prestaciones relativas al diagnóstico, tratamiento y rehabilitación de las enfermedades de transmisión sexual y a la provisión gratuitas de los métodos anticonceptivos tanto en los ámbitos privados como públicos. Por otra parte, establece las áreas del estado que tienen por responsabilidad la capacitación y formación de los agentes del estado para mejorar la prestación y asesoramiento en la temática. 
En cuanto a la provincia de Santa Cruz, podemos ver que mientras que por la Ley 2.656, (del 26 de junio de 2003), se adhiere a la ley nacional 25.673 para la creación del PNSSyPR pero sin erogación de fondos provinciales, en el 2010, se sanciona una nueva Ley 3.175 que deroga la anterior y establece, ahora sí, la asignación presupuestaria para el sostenimiento y efectiva implementación del programa en la provincia. Dos aspectos a considerar son que la ley provincial, a diferencia de la ley nacional establece explícitamente el objetivo de focalizar en los sectores más vulnerables de la sociedad y en segundo lugar, es elaborado por el Programa Provincial Materno Infantil, dependiente de la Subsecretaría de Salud Pública, dependiente del Ministerio de Asuntos Sociales. Cabe señalar que recién en el año 2011, el Gobernador de la Provincia decide la creación del Ministerio de Salud (Ley 3200, del 5 de abril de 2011), separando entonces la Subsecretaría de Salud y sus áreas de competencia del Ministerio de Asuntos Sociales que se transforma en el Ministerio de Desarrollo Social.

Otra ley nacional de aplicación relativa a los derechos de niñxs y adolescentes y a las obligaciones concomitantes por parte del Estado es la Ley 26061 de Protección integral de niñas/os y adolescentes(promulgada en octubre del 2005 y que aborda hasta los 18 años de edad) que se articula, por lo menos en el caso de Santa Cruz, con las acciones planificadas en el Plan Estratégico de Salud 2011-2015- donde se específica una línea específica de abordaje integral de la salud de los/as adolescentes.

Retomando La ley 25673, ésta alcanzará un mayor nivel de concreción que se expresará en la Ley 26.150 (sancionada el 4/10/06 y promulgada el 23/10/06) por la cual se crea el Programa Nacional de Educación Sexual Integral que dará una nueva tarea y función al sistema educativo, esto es, el abordaje obligatorio de la educación sexual. Tema que nuevamente volverá a discutirse en el año 2018 y que concitó no pocos debates en la sociedad (en el marco de las marchas pro despenalización del aborto que presionaron para el tratamiento legislativo del tema) expresándose en la propuesta de nuevas modificaciones a la ley (artículos 1,2,3,5,8,10 y 10 bis) que aún están en estado parlamentario (Expediente 5414-D-2018).

Los objetivos del Programa Nacional de Educación Sexual Integral refieren a incorporar la educación sexual integral dentro de las propuestas educativas orientadas a la formación armónica, equilibrada y permanente de las personas; asegurar la transmisión de conocimientos pertinentes, precisos, confiables y actualizados sobre los distintos aspectos involucrados en la educación sexual integral; promover actitudes responsables ante la sexualidad; prevenir los problemas relacionados con la salud en general y la salud sexual y reproductiva en particular; procurar igualdad de trato y oportunidades para varones y mujeres.

A partir de la sanción de esta Ley el Ministerio de Educación, Ciencia y Tecnología elaboró toda una serie de cuadernillos didácticos para los diversos niveles y modalidades en base a los lineamientos curriculares básicos para la educación sexual integral que fueran aprobados por el Consejo Federal de Cultura y Educación.

La provincia de Santa Cruz, adhiere a la Ley Nacional 26.150 por la Ley 3.043, sancionada el 12/03/2009 y promulgada el 06/04/2009, cuyo texto no propone especificación alguna respecto de su implementación en la región.

Respecto de los métodos anticonceptivos cuya provisión se establece como obligatoria por la legislación, la Resolución 65/15 del Ministerio de salud (Marco interpretativo del CCyC) explicita que todos los métodos anticonceptivos transitorios (incluidos los implantes y DIU) no son prácticas invasivas que comprometan el estado de salud. Por la Ley 26.130 de Anticoncepción quirúrgica del Congreso Nacional Sancionada: agosto 9 de 2006 y Promulgada: agosto 28 de 2006 se añade al artículo 6 $6^{\circ}$, de la Ley 25.673 de creación del PNSSyPR la aceptación de la ligadura de trompas de Falopio y ligadura de conductos deferentes o vasectomía como métodos de planificación familiar y/o anticoncepción. Esta 
salvedad resulta relevante por cuanto el Código Civil y Comercial de la Nación (2014, art. 26) establece que "el adolescente entre trece y dieciséis años tiene aptitud para decidir por sí respecto de aquellos tratamientos que no resultan invasivos, ni comprometen su estado de salud o provocan un riesgo grave en su vida o integridad física"; mientras que si se trata de tratamientos invasivos que comprometen su estado de salud o está en riesgo la integridad o la vida, el adolescente debe prestar su consentimiento con la asistencia de sus progenitores. A partir de los dieciséis años el adolescente es considerado como un adulto para las decisiones atinentes al cuidado de su propio cuerpo.

Resulta pertinente señalar también que la provincia de Santa Cruz, (por Resolución 540/2012 Ministerio De Salud) adhiere a la Guía Técnica para la Atención Integral de los Abortos No Punibles del PNSSyPR (junio del 2010) siendo de implementación en todos los Hospitales Públicos y Establecimientos Privados de la provincia.-

En 2017 el Programa Nacional de ESI se incluye en el "Plan Nacional de disminución de embarazo no intencional en la adolescencia", acción intersectorial coordinada por la SENNAF en la que participan los Ministerios de Educación, Salud, Desarrollo Social y la Fundación CIPPEC (Res. CFE N0322/17 Villa Carlos Paz, Córdoba, 21 de junio de 2017) donde se continúa con acciones de capacitación y producción de materiales educativos.

En el marco de los derechos sexuales, resulta pertinente consignar la Ley 26.743, que sanciona el derecho a la Identidad de género (mayo 2012), cuyo ejercicio se halla sujeto en personas menores de dieciocho (18) años de edad a que la solicitud del trámite sea efectuada a través de sus representantes legales y con expresa conformidad del menor (en conformidad con lo estipulado en la Convención sobre los Derechos del Niño y en la Ley 26.061). En caso de no contar con el consentimiento de alguno/a de los/as representantes legales, se podrá recurrir a la vía sumarísima para que los/as jueces/zas correspondientes resuelvan, teniendo en cuenta los principios de capacidad progresiva e interés superior del niño/a.

La Ley nacional 26.657/10 de derecho a la protección de la salud mental (reglamentada Decreto 603/13) hace también mención especial de niños, niñas y adolescentes (art. 26), en lo relativo a internaciones, estableciendo el deber de proceder de acuerdo a la normativa nacional e internacional de protección integral de derechos.

De lo señalado precedentemente se puede notar que en un período de 17 años se han promulgado un conjunto de leyes que sancionan un abanico de derechos para el conjunto de la población, y en particular para la niñez y adolescencia, que puso en la agenda pública la cuestión de la sexualidad y, recientemente, el embarazo no intencional adolescente en el foco de las intervenciones de las políticas públicas. Si bien el avance en el campo legislativo y normativo ha sido significativo no sólo en nuestro país sino en el Cono Sur (UNFPA, 2017), las leyes son condición necesaria pero no suficiente para el ejercicio de los derechos. En lo que respecta a la provincia encontramos la adhesión a los cambios que se propiciaron a nivel nacional recién en el año 2009 (ESI) y 2010 (PNSSyPR con asignación de financiamiento) sin que se presente alguna precisión que dé cuenta de la singularidad en territorio.

Por último, y según el relevamiento llevado a cabo en el año de investigación resta realizar un análisis más minucioso respecto de los enunciados, conceptos y categorías en todas las leyes tales como la noción de "derechos sexuales", "salud sexual", "intencionalidad", "identidad de género", y las formas en que es pensada "la/s adolescencia/s" ("menor/adulto"), dado que el modo que asume la enunciación determina las formas de intervención y por ende, sus resultados. 


\section{SISTEMATIZANDO LOS DATOS: EL VALOR DE LA LECTURA SITUADA E HISTÓRICA.}

\subsection{Los datos a nivel país y provincia ${ }^{1}$ : construyendo una serie histórica comparativa.}

Resulta pertinente iniciar este apartado señalando los datos que dan cuenta de la magnitud del fenómeno a nivel mundial para luego contextualizar la situación a nivel nacional y provincial. Así, cada año quedan embarazadas en el mundo 16 millones de niñas entre 15 y 19 años, y 2 millones de niñas de menos de 15 años. "A nivel mundial el $90 \%$ vive en países de ingresos bajos y medios, y sólo el $51 \%$ asiste a los años superiores de la escuela secundaria ${ }^{3}$. La tasa global de embarazo adolescente y/o tasa media de natalidad muestra un nivel alto estimado en 49 por 1.000 mujeres de entre 15 y 19 años, con amplias diferencias entre países ricos y pobres; siendo las más alta la del África Subsahariana y siguiéndole Latinoamérica y el Caribe" (Amnistía Internacional, pág. 1)

Según datos de la ONU (2017, Educación 2050) países desarrollados como EEUU y Reino Unido mantienen tasas elevadas (24, y 15,53 respectivamente) pero que son muy inferiores si se compara con África y América Latina y el Caribe que mantienen tasas de 103 y 64,57. Un elemento a considerar es que en las regiones como ALyC mantienen tasas altas fuera de matrimonio, en Asia meridional tasas altas dentro de matrimonio y en África ambos escenarios.

En nuestro país, el 15\% del total de los nacimientos corresponden a madres adolescentes (de entre 10 y 19 años de edad), siendo un dato que se mantiene estable desde los últimos 25 años. Los datos oficiales indican que, de manera sostenida, alrededor de 3.000 nacimientos al año corresponden a madres menores de 15 años.

Resulta relevante señalar que los datos demográficos disponibles en nuestro país podrían adolecer de sesgos metodológicos dadas las situaciones presentadas en torno al Censo Nacional de Población, Hogares y viviendas 2010, en el que se encontraron aproximadamente 400.000 casos de réplicas o clonación (traspolación de los datos de una población a otra) de registro de población y hogares 2010. Las duplicaciones van de dos hasta 130 veces de registros de individuos, en 94 casos los mismos se replicaron 130 veces. $\mathrm{Si}$ bien todo censo tiene errores y omisiones, éstas no fueron especificadas, habiéndose presentado una denuncia penal por el INDEC. Por otro lado, durante el 2016 y 2017 la DEIS realiza, con apoyo de UNICEF y Centro de Estudios de la población (CENEP), una investigación sobre cobertura del registro de nacimientos destinado a evaluar el estado actual de la omisión de registro y las demoras en la inscripción de los nacimientos para el total del país y por jurisdicción. La Omisión de nacidos vivos que surge de comparar los datos que brinda el censo 2010 con los nacidos vivos registrados por el subsistema de estadística vital es del $6 \%$ para el total del país si se toman como referencia los datos publicados para el mismo año, y se reduce al 3,8\% si se consideran las inscripciones tardías que se produjeron a lo largo de los años 2011 a 2014. Santiago del estero, Santa fe y Tierra del Fuego tienen valores del 10\%. Para el año 2016, se verifica una baja considerable en el número registrado de nacimientos en todas las jurisdicciones, lo cual podría deberse a problemas en la cobertura, que persisten a pesar del trabajo sostenido, en algunas jurisdicciones o bien al desarrollo de la propia dinámica demográfica. Y para la información de ese mismo año se destaca que fue necesario realizar un estudio de omisión de registro de causas de mortalidad

\footnotetext{
${ }^{1}$ La Provincia de Santa Cruz se encuentra ubicada entre los paralelos 46 y 52 y los meridianos 59 y 73 . Con una superficie de $243.943 \mathrm{~km}^{2}$, se extiende sobre $710 \mathrm{~km}$ de norte a sur y su ancho varía entre $482 \mathrm{~km}$ al norte y 219 $\mathrm{km}$ al sur. Es la segunda en extensión en nuestro país y también la de menor población, no obstante lo cual presentó la mayor tasa de crecimiento intercensal 2001 - 2010. Los departamentos de Güer Aike y Deseado (al que pertenece la localidad de Caleta Olivia) concentran alrededor del 85\% de los habitantes de la Provincia.
} 
materna de alcance nacional. Especial interés para la temática en estudio reviste el hecho de que los nacimientos que se registran luego de 6 meses o del año de ocurridos tienen porcentajes mayores en madres adolescentes que, al momento del nacimiento no convivían en pareja, que cuentan con menores niveles de instrucción y otras variables vinculadas con condiciones socioeconómicas más desfavorables.

Hecha esta salvedad, a partir de los datos disponibles se construyó una serie histórica comparativa a efecto de analizar la evolución de la tasa de fecundidad adolescente durante el período 1990 - 2016.

Se presenta a continuación la evolución a nivel país de la tasa de fecundidad adolescente (10 a 19 años de edad) para el citado período (gráfico 1), en la que se observa que la misma se ha mantenido relativamente estable, variando de un mínimo de 28,8 (en el 2016) a un máximo de 35, 3 alcanzado en el año 2011. Como señalan fuentes oficiales la leve disminución entre 2015 y 2016 no puede aún considerarse una tendencia. Y a esto hay que agregarle los ya mencionados problemas planteados judicialmente sobre el censo 2010.

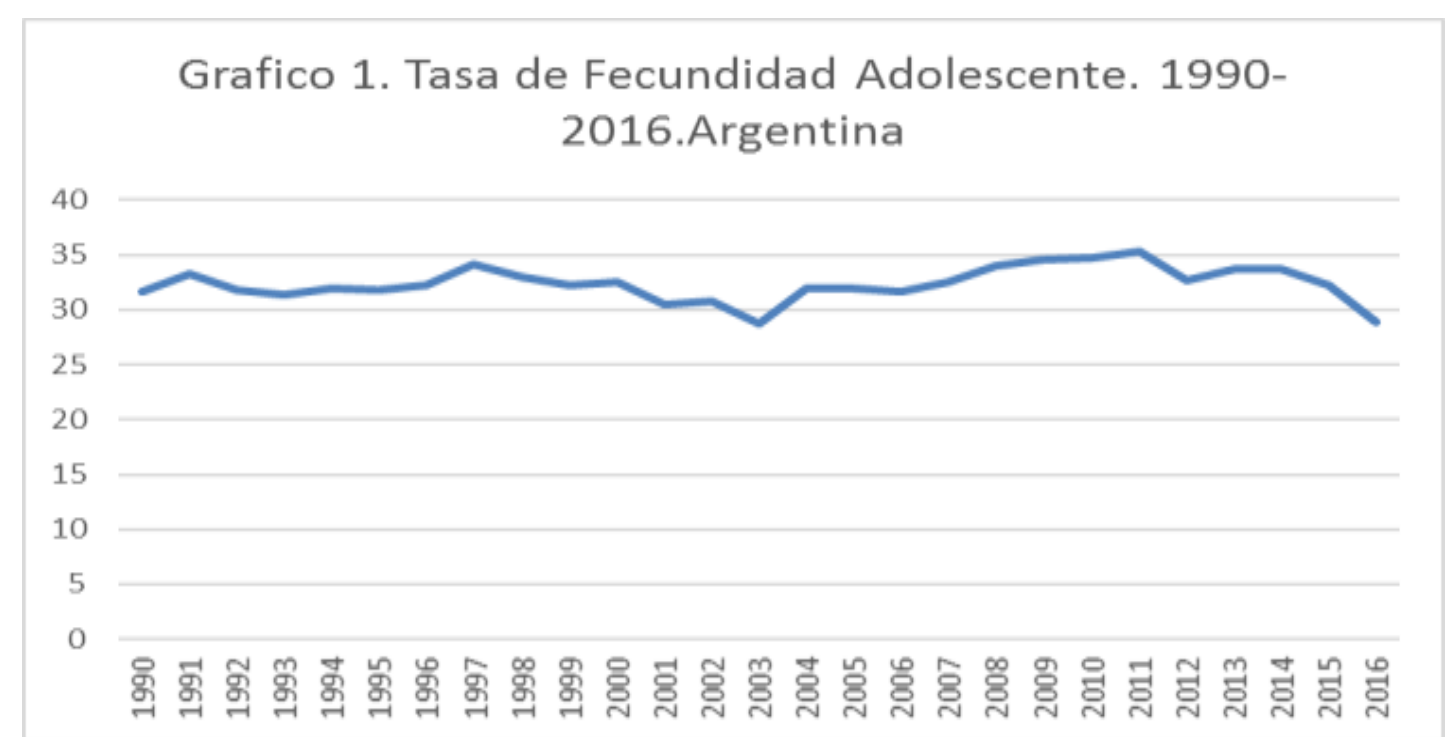

Elaboración propia. Fuente: Boletines de la Dirección de Estadísticas e Información en Salud (DEIS), Presidencia de la Nación.

Analizaremos a continuación qué ocurre en la provincia de Santa Cruz respecto de la tasa nacional en el mismo período. 


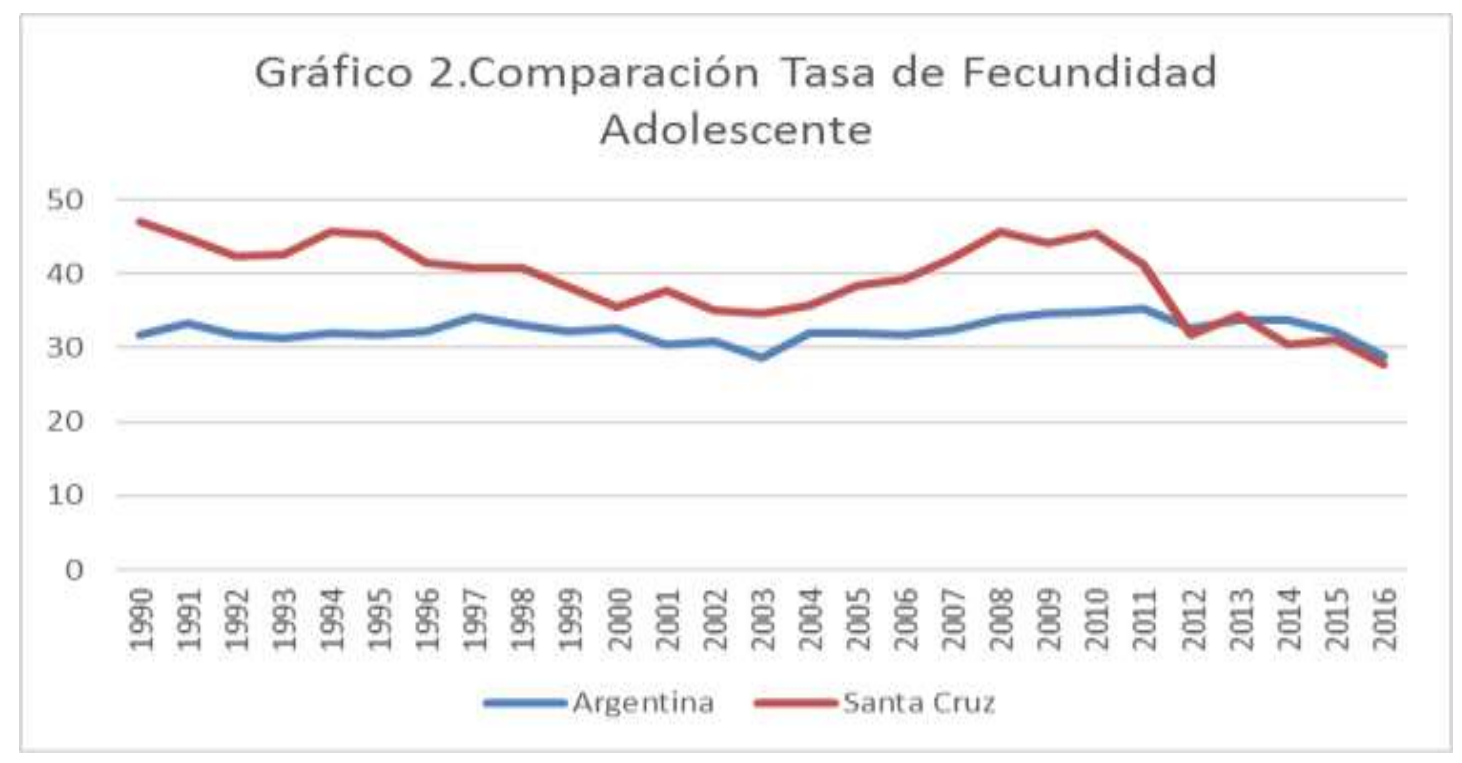

Elaboración propia. Fuente: Boletines DEIS, Presidencia de la Nación.

En el gráfico 2 podemos observar que en Santa Cruz la tasa de fecundidad estuvo, desde el año 1990 al 2012, muy por encima de la tasa nacional. Mientras que la tasa nacional a inicios del período era de 31,7 en la provincia de Santa Cruz alcanzaba un valor de 47, teniendo un nuevo pico en el 2010 (45,5), luego de lo cual presenta un descenso significativo de más de 10 puntos del 2011 al 2012 lo que podría llevar a problematizar el registro de datos o estadísticas en la provincia puesto que es difícil imaginar una variable de intervención que produzca tal reducción abrupta en sólo un año. Es difícil de imaginar variables como cambios de comportamiento sexual-reproductivo por parte de '1xs adolescentes para tamaña reducción como incomprensible que de haber habido una intervención "agresiva" por parte del estado, no se continuara con dicha acción dada su eficacia puesto que luego aumenta hasta superar la del estado nacional en el año 2013 para nuevamente descender a la media nacional del 2014 al 2016. Estos datos ameritan un estudio más exhaustivo del caso provincial, dada la irregularidad de la evolución observada, y los datos (según el informe DEIS-MS, para el año 2010) sobre la población de mujeres adolescentes que en la provincia era de 21.434 y para el 2011 era de 21.401. Descenso que se repite a nivel nacional donde en 2010 alcanzaba a 3.377.475 y para el 2011 disminuyó a 3.368.425.

Por otro lado, en los estudios de tasa de fecundidad adolescente (10 a 19 años) tanto a nivel nacional como en los datos internacionales las estadísticas indican que a mayor índice de desarrollo humano menor tasa de fecundidad. Ahora bien, en la provincia de Santa Cruz, en el período de mayor avance socioeconómico (expresado en el crecimiento intercensal y el dinamismo económico) la tasa de fecundidad adolescente aumenta, lo que refuta todas las experiencias internacionales y los análisis académicos realizados hasta el momento. Más claramente, a mayor bienestar se debería reducir la tasa. Esto no sucede en nuestra provincia si tenemos en cuenta que si bien el Producto Bruto Geográfico (PBG) de Santa Cruz representa el 1,5\% del Producto Interno Bruto nacional (PIB), su producto per cápita es cerca de dos veces y media superior al nacional (Plan estratégico de salud 2011 - 2015 Ministerio de Salud, gobierno de Santa Cruz, octubre 2011).

Resulta aún más significativa la singularidad del caso santacruceño si consideramos la distinción entre tasa temprana (10 a 14 años) y tardía (15 a 19 años). 


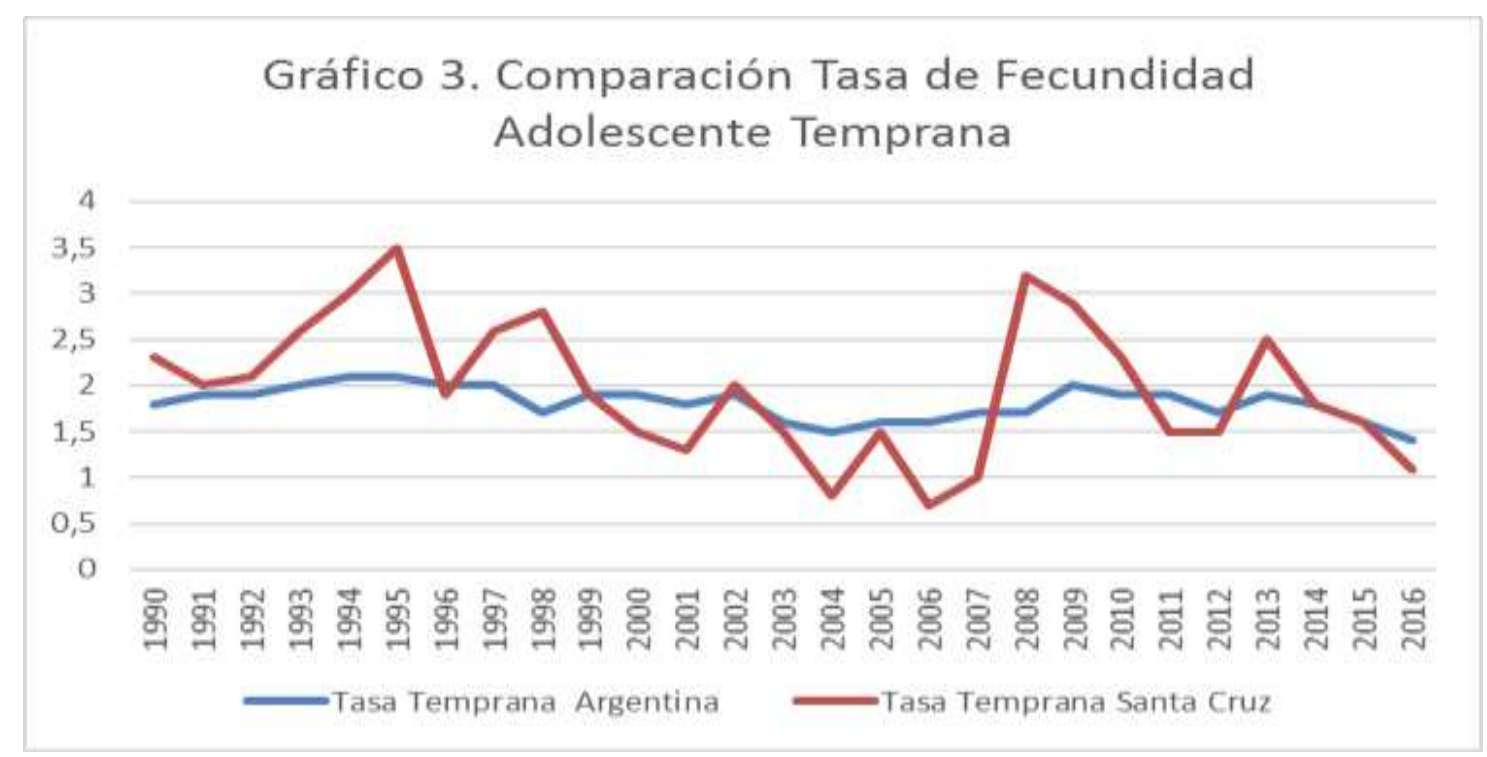

Elaboración propia. Fuente: Boletines DEIS, Presidencia de la Nación.

En el período considerado la provincia de Santa Cruz presenta muy significativas variaciones que van de un mínimo de 0,7 a un máximo de 3,5 (es decir que la tasa se quintuplica), mientras que el rango de variación a nivel nacional es mucho más acotado (oscilando de 1,4 a 2,1). No solamente las variaciones son mucho mayores, sino que son abruptas, alternándose los picos y descensos en períodos muy breves de tiempo, por ejemplo, del 0,7 en el 2006 a 3,2 en el 2008. ¿Qué explicaría tamañas diferencias en las oscilaciones en la provincia?

Un aspecto, no menor, a considerar es que la tasa temprana refiere directamente a situaciones de violación y abuso sexual, por tratarse de menores/adolescentes de 10 a 14 años. Difícilmente, sin caer en el oprobio, podría sostenerse un argumento en el orden del deseo (o de prácticas sexuales intencionales/consentidas) en cuanto a maternidad se refiere, considerando, incluso, que se exponen a cuatro veces más riesgo de muerte comparado con las madres de más de 20 años, según estudios que recuperan cifras oficiales.

Si bien los datos del Sistema Nacional de Información Criminal (SNIC) no se hallan discriminados por grupo de edad, no podemos dejar de mencionar, en este contexto, que en cuanto a violaciones la provincia de Santa Cruz ocupa el noveno lugar a nivel nacional, siendo además la que presenta el mayor crecimiento interanual (en 2014 la tasa era de 2.2 víctimas de violación cada 100 mil habitantes, pasando en el año 2015 a 9,4 violaciones cada 100 mil habitantes y a 10,6 en el 2017). Es preciso señalar también que es un hecho reconocido el subregistro de las violaciones y casos de abuso sexual (con lo cual, sabemos que las cifras - ya alarmantes - son aún mayores); sobre todo tratándose de niñas de 10 a 14 años en cuyo caso la evidencia indica que los abusos ocurren en el seno de la familia, en función de lo cual es todavía más improbable que se denuncien, y lleguen así a las estadísticas. 


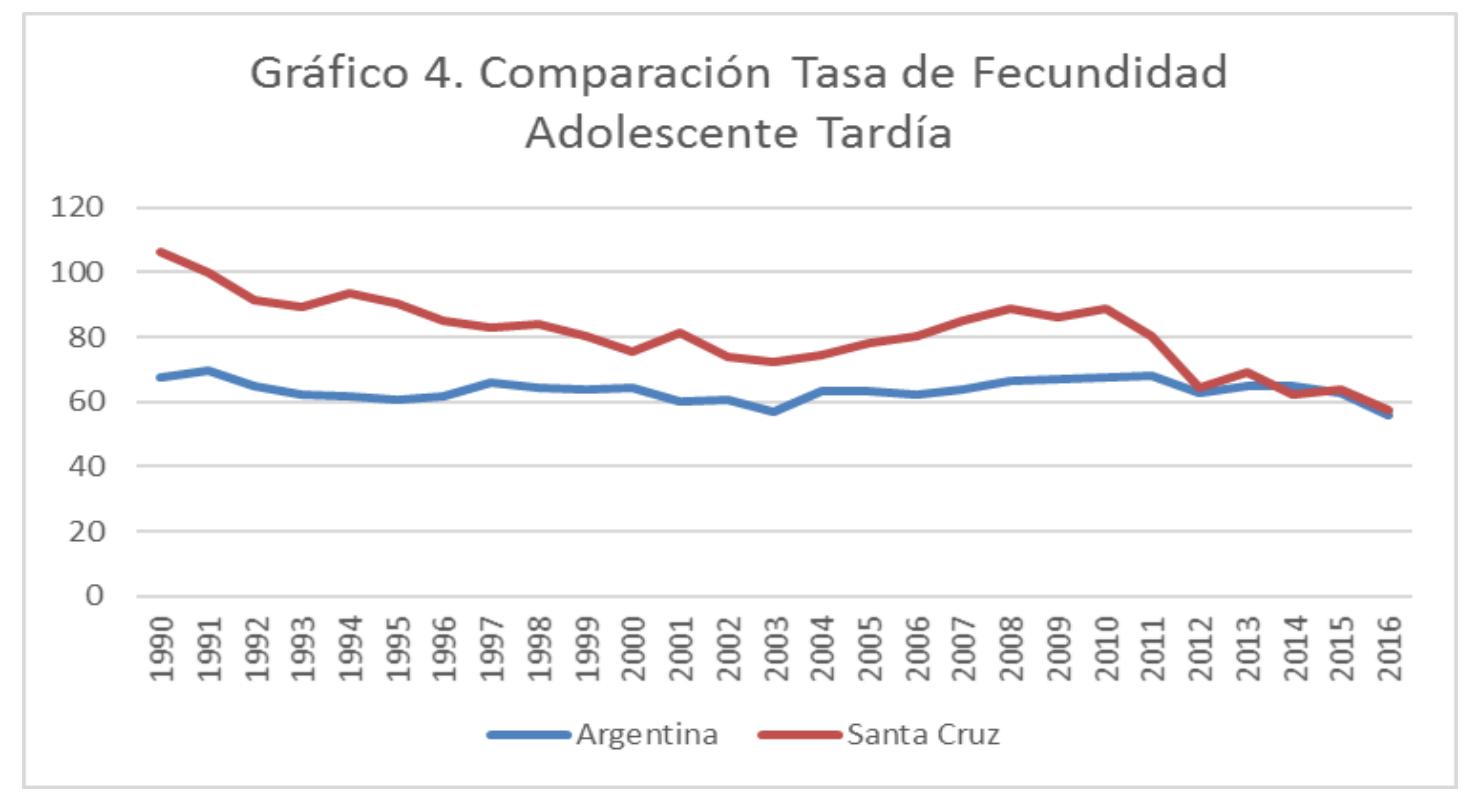

Elaboración propia. Fuente: Boletines de la Dirección de Estadísticas e Información en Salud, Presidencia de la Nación

En el gráfico 4 se observa que los valores provinciales se hallan muy por encima de los nacionales, situándose al inicio del período estudiado en 106, 3 mientras que la tasa nacional era de 67, 3. A partir de allí se inicia un tendencia descendente seguida por un crecimiento sostenido desde el 2004 al 2008 distanciándose nuevamente de los valores nacionales. 2014 es el único año en toda la serie en que la tasa de fecundidad provincial está por debajo de la nacional (62 mientras que a nivel país era de 65,1). Al igual que lo sucedido con la tasa de fecundidad adolescente, en el caso específico de la tasa tardía en el año 2012 se produce un brusco descenso respecto del año anterior que va de 80, 5 a 64,2 (mientras que a nivel nacional desciende 5 puntos, en la provincia disminuye 16 puntos). A riesgo de ser reiterativas debe señalarse nuevamente el problema de la construcción de los datos oficiales. A ese respecto, vale remarcar que los datos sobre la fecundidad tardía no contemplan/consideran los egresos hospitalarios por aborto, por ejemplo, de los registrados en el país en el 2012 un $18.42 \%$ correspondió a mujeres menores de 20 años y si se pone la mirada en los años anteriores se verifica que desde el año 1995 al 2013 se registra un aumento del peso de las mujeres adolescentes en la población de mujeres de todas las edades que son hospitalizadas por esta causa (Amnistía Internacional, pág. 13). Estos datos indican una mayor incidencia del embarazo adolescente que la registrada al considerar la tasa de fecundidad en la medida en que, como ya se ha señalado, la misma parte del registro de los nacidos vivos.

Otra dimensión importante del fenómeno del embarazo adolescente son los casos de su repitencia. Un quinto de los nacimientos que ocurren anualmente en adolescentes son de orden 2 o más, es decir de madres adolescentes que ya han tenido uno o más hijos. El estudio de Gogna y Binstock señala que una importante proporción de los segundos embarazos entre adolescentes no es planeada. Esto es, no se logra generar un adecuado seguimiento por parte de los servicios de salud que permita brindar herramientas concretas a jóvenes y adolescentes que atraviesan un primer embarazo para prevenir futuros embarazos no deseados (Amnistía Internacional, pág. 13)

Frente a este panorama, tanto a nivel país como provincia, no ha habido mermas significativas en la tasa de fecundidad si se las compara con la década 'del 90 donde no hubo políticas públicas dirigidas al fenómeno de la maternidad adolescente. Queda entonces por pensar seriamente no sólo cómo se piensa el fenómeno sino cómo se evalúan las políticas públicas puesto que los datos estarían dando cuenta de la ineficacia de las mismas o de la 
complejidad del problema y la deuda pendiente académica respecto de las variables más significativas en la producción de la situación de las y los adolescentes.

\subsection{Los datos sobre programas y planes.}

En este apartado abordaremos los planes y programas que forman parte de las políticas públicas relacionadas con el fenómeno objeto de estudio, que se diseñaron e implementaron en las últimas dos décadas en Argentina. Hemos categorizado por el formato de acción según objeto de intervención social resultando cinco tipos: 1. Programas relativos a la formación y prevención en salud sexual y procreación responsable; 2. Planes relativos a formación y prevención en SSyPR, 3. Promoción de la salud, asistencia a adolescentes y madres adolescentes, 4. Asistencia monetaria durante el embarazo, y 5. Asistencia monetaria a la infancia. En dichos programas y planes intervienen diferentes dependencias estatales e instituciones que se indican en los cuadros a continuación para cada uno de los tipos señalados. Por último, se presentan datos relevados a partir de la indagación realizada de los presupuestos involucrados en algunas de las acciones, habida cuenta de que la incorporación de derechos implica necesariamente la generación de las condiciones para su ejercicio, y según analizaremos más adelante - la protección de los derechos tiene un costo, que resulta necesario poner en cuestión.

\section{A) Programas relativos a formación y prevención en SSyPR}

\begin{tabular}{l|l|l|}
\hline $\begin{array}{l}\text { Denominación } \\
\begin{array}{l}\text { Programa Nacional de Salud Sexual y } \\
\text { Procreación Responsable (PNSSyPR) }\end{array}\end{array}$ & $\begin{array}{l}\text { Ley 25.673 } \\
\text { Inicia 2003 }\end{array}$ & $\begin{array}{l}\text { Ministerio de Salud Dirección de salud } \\
\text { sexual y reproductiva }\end{array}$ \\
\hline $\begin{array}{l}\text { Programa Nacional de Educación Sexual } \\
\text { Integral }\end{array}$ & $\begin{array}{l}\text { Ley 26150 } \\
2006 \text { y } \\
\text { continúa }\end{array}$ & $\begin{array}{l}\text { Ministerio de Educación de la Nación } \\
\text { Programa ESI }\end{array}$ \\
\hline $\begin{array}{l}\text { Programa Nacional de salud integral en la } \\
\text { adolescencia (incluye Programa SUMAR- } \\
\text { PROSANE-Asesorías en salud integral en } \\
\text { escuelas secundarias) }\end{array}$ & MDS-MS \\
$\begin{array}{l}\text { Programa Municipios y comunidades } \\
\text { saludables }\end{array}$ & 2008 & MSAL \\
\hline $\begin{array}{l}\text { Programa "Hablemos de todo" plataforma } \\
\text { digital }\end{array}$ & 2017 & $\begin{array}{l}\text { Dirección Nacional de la Juventud, } \\
\text { Subsecretaría de Juventud, MDS }\end{array}$ \\
$\begin{array}{l}\text { Programa FoCo ETP, } \\
\text { Ministerio de Educación-INET }\end{array}$ \\
\hline $\begin{array}{l}\text { MECyCyT en convenio con } \\
\text { MSyDSocial. }\end{array}$
\end{tabular}

Las acciones del PNSSyPR, desde su creación hasta el 2006, se centraron en la entrega de insumos (métodos anticonceptivos e instrumental para colocación de DIU) a las provincias para su distribución gratuita en los Centros de Atención Primaria y hospitales públicos, a solicitud de las/los usuarias/os, con asesoramiento o consejería especializada (a fines de ese año los centros de salud y hospitales con prestaciones del Programa superaban los 6100 en todo el país, siendo 1.900.000 usuarias/os). Asistió asimismo técnicamente a las autoridades provinciales, para la implementación de programas locales en todas las provincias, brindando capacitación a los equipos de salud mediante la articulación con el Programa de Médicos Comunitarios y 
produciendo, para entrega de forma gratuita, materiales didácticos de difusión para actividades de comunicación social y campañas. A partir del 2006 se añaden a ello una serie de acciones dirigidas a generar los recursos humanos y materiales para la difusión de la ESI, convocando una Comisión Interdisciplinar e intersectorial y asesorando la elaboración de los Lineamientos Curriculares de Educación Sexual Integral (ESI) y la creación del Programa Nacional.

Creado el Programa ESI, a partir de 2009 se distribuyen materiales educativos para todas las jurisdicciones (posters, cuadernillos, folletos, láminas para aulas, cortos de televisión, revistas para familias), disponibles actualmente en la ESIteca. Las capacitaciones se dan tanto de manera virtual (desde el 2008, capacitándose más de 30.000 docentes) como presencial (hasta el 2012 habían participado 50.000 docentes) totalizando hasta el 2017,218.450 docentes capacitados (no es posible precisar si ese número representa cantidad de personas dado que un mismo docente puede haber participado de ambas instancias). En cuanto al número de escuelas, participaron de las capacitaciones 44.450 establecimientos educativos. Según la información relevada la provincia de Santa Cruz participa de las mismas en el año 2014, lo que converge con la creación del programa y asignación presupuestaria (2010) pudiéndose ver un ingreso tardío al abordaje de la temática respecto de lo que promovió Nación (situación llamativa y que requiere mayor indagación teniendo en cuenta el signo político compartido).

Las acciones del Programa Nacional de salud integral en la adolescencia, están orientadas a la difusión de información: materiales para la población (afiches uso preservativo, programa sumar, cobertura salud adolescentes), materiales para equipos de salud (materiales 2018 adolescentes y salud, materiales asesorías en salud integral en escuelas secundarias, programa de salud escolar manuales de instrucción y programa municipios y comunidades saludables elaboración de boletines). La misma intención formativa se verifica en el Programa En FoCo ETP, cuya especificidad radica en el de tener como destinatario el personal de las instituciones de Educación Técnico Profesional (especialmente EPJAs) y el Programa Municipios y comunidades saludables, que tiene como propósito fortalecer las acciones de promoción de la salud en el nivel local y mejorar los resultados en salud (cabe consignar que ninguno de los municipios de la provincia de Santa Cruz participa del programa.)

Respecto del Programa "Hablemos de todo", su particularidad consiste en una plataforma digital y número gratuito donde los/as adolescentes pueden recurrir para consultas y asistencia ante situaciones de embarazo adolescente ampliándose a problemáticas como suicidio, bullying, identidad de género, entre otras.

Comenzamos a ver cómo se va configurando un entramado de diferentes ministerios y dependencias donde el énfasis, respecto de la problemática, radica en la formación y la capacitación siendo los adultos/as intermediarios/as, a excepción del "Hablemos de todo" que se dirige focalizadamente a los/as adolescentes. Entendemos entonces que la mayoría de las acciones parecen sostenerse en una de las variables del fenómeno, respecto de la asociación información-educación y embarazo adolescente, dejando de lado otras dimensiones que podrían potencialmente abonar la explicación de la persistencia del fenómeno pese a la multiplicidad de programas y acciones llevadas a cabo para su prevención. 


\section{B) Planes relativos a formación y prevención en SSyPR}

\begin{tabular}{|c|c|c|c|}
\hline Denominación & Año/Leyes & Dependencias & Característica \\
\hline $\begin{array}{l}\text { Plan nacional } \\
\text { de abordaje } \\
\text { Integral. Plan } \\
\text { Ahí (acceso a } \\
\text { la salud integral } \\
\text { para la } \\
\text { población más } \\
\text { vulnerable) }\end{array}$ & $\begin{array}{l}\text { Decreto } \\
621 / 08\end{array}$ & MSAL y DS & $\begin{array}{l}\text { Problemática Adolescente: indagar, cuestionar y } \\
\text { reflexionar sobre lo que el sentido común entiende } \\
\text { por "el problema del embarazo adolescente". Trata } \\
\text { de poner en foco la naturaleza social e histórico- } \\
\text { cultural del concepto de adolescente. }\end{array}$ \\
\hline $\begin{array}{l}\text { Plan Nacional } \\
\text { de Prevención } \\
\text { y Reducción } \\
\text { del Embarazo } \\
\text { no Intencional } \\
\text { en la } \\
\text { Adolescencia } \\
\text { (ENIA) }\end{array}$ & $\begin{array}{l}N^{\circ} \\
\text { RESOL- } \\
2017- \\
1790- \\
\text { APN- } \\
\text { MDS }\end{array}$ & $\begin{array}{l}\text { SENNAF- } \\
\text { MDS }\end{array}$ & $\begin{array}{l}\text { Acceso gratuito a métodos anticonceptivos, } \\
\text { coordina con PNESI y asesorías en SSySR y } \\
\text { hablemos de todo. } \\
\text { Semana "Querer posta" septiembre } 2017 \text { (FEIM), } \\
\text { UNICEF, la Red Nacional de Jóvenes y } \\
\text { Adolescentes para la Salud Sexual y Reproductiva } \\
\text { (RedNac), Amnistía Internacional, FUSA AC, el } \\
\text { Equipo Latinoamericano de Justicia y Género } \\
\text { (ELA) y Fundación Huésped, programa } \\
\text { "Hablemos de todo" de la DNJ }\end{array}$ \\
\hline $\begin{array}{l}\text { Plan Nacional } \\
\text { de Acción en } \\
\text { Derechos } \\
\text { Humanos }\end{array}$ & $2017-2020$ & $\begin{array}{l}\text { MDS } \\
\text { (SENNAF) } \\
\text { COFENAF y } \\
\text { MdJ y DDHH }\end{array}$ & $\begin{array}{l}\text { En el marco del PN ENIA desarrolla: talleres de } \\
\text { salud sexual reproductiva ( } 7000) \text { y talleres de buen } \\
\text { trato y cuidado del cuerpo ( } 6 \text { a } 12 \text { años) objetivo } \\
420.000 \text { niños y adolescentes }\end{array}$ \\
\hline $\begin{array}{l}\text { "El ENIA: su } \\
\text { abordaje desde } \\
\text { la escuela } \\
\text { secundaria" }\end{array}$ & $\begin{array}{l}\text { Anexo } \\
\text { Resolución } \\
\text { CFE } \\
\text { N0322/17 }\end{array}$ & $\begin{array}{l}\text { Secretaría de } \\
\text { Innovación y } \\
\text { calidad } \\
\text { educativa y } \\
\text { jurisdicciones } \\
\text { provinciales }\end{array}$ & $\begin{array}{l}\text { Capacitación y Producción de cartilla "Embarazo } \\
\text { no intencional en la adolescencia- Propuestas para } \\
\text { el aula", para distribuir en las escuelas que se } \\
\text { encuentran dentro del Plan. }\end{array}$ \\
\hline
\end{tabular}

Nuevamente, respecto de los planes (que se articulan con los programas previamente descriptos), se siguen sosteniendo en el supuesto de la necesidad de información y educación, pero se caracterizan por una implementación focalizada tanto territorialmente como etáreamente. A lo que ya habíamos caracterizado como un entramado de diferentes ministerios y dependencias, se incorporan asociaciones civiles. Vale remarcar que el Plan ENIA se enmarca en lo acordado en reuniones con representantes ministeriales del CONO SUR (acción que se había iniciado con una reunión en el año 2015) con el objetivo de evaluar las políticas públicas referidas al fenómeno del embarazo adolescente y la resistencia a una baja significativa de los datos en la región. En el documento que da cuenta del Acuerdo Regional se destaca que "el embarazo y la maternidad en la adolescencia es en la gran mayoría de los casos un problema de inequidad y desigualdad social. Las desigualdades son territoriales, étnicas, culturales, económicas, de género y educativas entre otras.” (pág, 9)”, ratificando lo anteriormente expuesto respecto de la insuficiencia de las políticas públicas que enfocan prioritariamente la provisión de información. Asimismo, centrar las intervenciones en el ámbito escolar implica dejar fuera de ellas al segmento de adolescentes que se embarazan una vez que dejaron la escuela, que representa según los estudios una "importante proporción". 
Entendemos que la inclusión reciente (2017) del Programa ESI en el Plan ENIA es una expresión de los acuerdos y orientaciones estratégicas consensuadas a nivel regional. Si bien podríamos valorar los lineamientos acordados (no parecen erróneos) resulta importante considerar que no devienen de evaluaciones del estado argentino. A tantos años de políticas públicas implementadas mediando una importante asignación presupuestaria, resultaría conveniente una evaluación y sistematización serias de las acciones desarrolladas.

\section{C) Promoción de la salud, asistencia a adolescentes y madres adolescentes}

\begin{tabular}{|c|c|c|c|}
\hline $\begin{array}{l}\text { Denominaci } \\
\text { ón }\end{array}$ & Año/Ley & \begin{tabular}{|l} 
Dependenci \\
$\mathbf{a}$
\end{tabular} & Características \\
\hline Plan Nacer & $\begin{array}{l}2005 \text { y } \\
\text { continúa. }\end{array}$ & Anses- & $\begin{array}{l}\text { Proyecto de inversión en salud materno infantil. Cobertura } \\
\text { a embarazadas, puérperas hasta } 45 \text { días y niños/as menores } \\
\text { de } 6 \text { años que no tienen obra social. Finalidad: disminuir } \\
\text { índices de morbimortalidad materno infantil fortaleciendo la } \\
\text { red pública de APS. } \\
\text { Evaluación del impacto 2004-2012: aumentó uso y mejoró } \\
\text { calidad de servicios de atención prenatal, menor incidencia } \\
\text { de bajo peso al nacer }(<2,5 \mathrm{~kg}) \text { y menor mortalidad neonatal } \\
\text { en los hospitales (- } 22 \% \text { probabilidad de muerte neonatal en } \\
\text { hospitales entre usuarios de clínicas del Plan Nacer y - } 74 \% \\
\text { entre beneficiarios del Plan Nacer. } \\
\text { Financiamiento: Gob. prov. recibieron pagos por capitación } \\
\text { del MSAL según } \mathrm{N}^{\circ} \text { de beneficiarios inscriptos y logro de } \\
\text { metas según indicadores sanitarios. Centros de salud reciben } \\
\text { de Gobiernos pciales remuneración según número y calidad } \\
\text { de servicios prestados }\end{array}$ \\
\hline $\begin{array}{l}\text { Programa } \\
\text { Sumar }\end{array}$ & 2012 & Anses- & $\begin{array}{l}\text { Amplía plan Nacer. Cobertura de salud a niños/as, } \\
\text { adolescentes, embarazadas, hombres y mujeres hasta } 64 \\
\text { años que no tienen obra social ni prepaga. } \\
\text { El centro de salud, hospital o CIC, recibe recursos para } \\
\text { fortalecer equipo de salud y mejorar servicios brindados a } \\
\text { la comunidad, por nro inscriptos en Programa y por } \\
\text { consulta y control registrado. }\end{array}$ \\
\hline
\end{tabular}

Respecto de estas acciones se trata de políticas compensatorias donde si bien padres/madres adolescentes pobres están considerados/as como un sector de la población vulnerable que necesita especial atención, en concreto no hay coberturas específicas destinadas a ellos/as, sino a sus hijos/as que resultan destinatarios de los beneficios / prestaciones, pero no acceden a ellos con exclusividad, sino en igualdad de condiciones respecto de los otros grupos de edad. Esto presupone que no se están atendiendo a otras variables relativas a las condiciones materiales de vida de un/a adolescente tales como situación habitacional, posibilidades de ingreso a un trabajo formal (de hecho, es una franja etárea fuertemente afectada por la desocupación), dependencia familiar o maternidad en soledad, entre otras. 


\section{D) Asistencia monetaria durante el embarazo}

\begin{tabular}{|c|c|c|c|}
\hline Denominación & LEY/año & Dependencia & Características \\
\hline $\begin{array}{l}\text { Asignación } \\
\text { familiar por } \\
\text { embarazo para } \\
\text { protección } \\
\text { social (AUE) }\end{array}$ & $\begin{array}{l}\text { Dec. } \mathrm{N}^{\circ} \\
702 \text { y Res. } \\
\text { ANSES N } \\
125 / 2018\end{array}$ & ANSES & $\begin{array}{l}\text { Pago mensual que realiza ANSES a mujeres } \\
\text { embarazadas desde semana } 12 \text { de gestación } \\
\text { hasta nacimiento o interrupción del embarazo, } \\
\text { (supeditada a inscripción en Programa } \\
\text { SUMAR, excepto Trabajadoras del Servicio } \\
\text { Doméstico, de Temporada y Monotributistas } \\
\text { Sociales - y cumplimiento de controles } \\
\text { médicos establecidos por el Programa). Monto: } \\
\$ 2.190 .-\$ 1.752,00(80 \%) \text { - } \$ 438,00(20 \%) \text {. }\end{array}$ \\
\hline $\begin{array}{l}\text { Asignación } \\
\text { familiar por } \\
\text { prenatal }\end{array}$ & $\begin{array}{l}\text { Dec. } \mathrm{N}^{\circ} \\
702 \text { y Res. } \\
\text { ANSES N } \\
125 / 2018\end{array}$ & ANSES & $\begin{array}{l}\text { Pago mensual que realiza la ANSES durante la } \\
\text { gestación y hasta el nacimiento o interrupción } \\
\text { del embarazo. Monto } \$ 3635 \text { (zona } 4 \text { ) desde } \\
\text { 01/09/18). IGF entre } \$ 3004,25 \text { y } \$ 26.129\end{array}$ \\
\hline
\end{tabular}

E) Asistencia monetaria a la infancia

\begin{tabular}{|c|c|c|c|}
\hline Denominación & Ley/año & Dependencia & |Características \\
\hline $\begin{array}{l}\text { Asignación } \\
\text { universal por } \\
\text { hijo }\end{array}$ & $\begin{array}{l}\text { Decreto } \\
N^{\circ} 702 \text { y } \\
\text { Resolución } \\
\text { ANSES N } \\
125 / 2018\end{array}$ & ANSES & $\begin{array}{l}\text { Lo perciben: Trabajadores en Relación de } \\
\text { Dependencia, Titulares de la Prestación de la LR } \\
\text { T, de Prestación por Desempleo, Jubilados y } \\
\text { Pensionados del Sistema Integrado Previsional } \\
\text { Argentino, Titulares de Pensiones Honoríficas de } \\
\text { Veteranos de Guerra del Atlántico Sur. Monto \$ } \\
\text { 3.635.- IGF entre \$3.004,25.- y \$ } 26.129\end{array}$ \\
\hline $\begin{array}{l}\text { Asignación } \\
\text { Universal por } \\
\text { HIJO para } \\
\text { PROTECCIÓN } \\
\text { SOCIAL }\end{array}$ & $\begin{array}{l}\text { Dec } N^{\circ} \\
702 \text { Res. } \\
\text { ANSES N } \\
125 / 18\end{array}$ & ANSES & $\begin{array}{l}\text { * } 80 \% \text { en la liquidación normal. ** } 20 \% \\
\text { acumulado de la Asignación Universal por Hijo e } \\
\text { Hijo con Discapacidad contra la presentación de la } \\
\text { Libreta Nacional de Seguridad Social, Salud y } \\
\text { Educación y DDJJ del Adulto Responsable. } 20 \% \\
\text { acumulado de la Asignación por Embarazo para } \\
\text { Protección Social contra la presentación del } \\
\text { Formulario "Solicitud Asignación por Embarazo } \\
\text { para Protección Social” con los rubros } 1 \text { y } 3 \\
\text { debidamente cumplimentados, adjuntando además } \\
\text { la constancia de Inscripción en el Plan Nacer/ } \\
\text { Programa SUMAR del recién nacido y la Partida } \\
\text { de Nacimiento o Certificado de } \\
\text { Defunción/Interrupción del Embarazo } \\
\text { Monto \$2.190.- } \$ 1.752,00 \text {. ( } 80 \%) \text { - } \$ 438,00 \\
\text { (20\%). }\end{array}$ \\
\hline
\end{tabular}

Tanto respecto de la categoría D) asignación monetaria durante el embarazo, como de la E) asistencia monetaria a la infancia, verificamos que se trata de políticas compensatorias, específicamente económicas, que en ambos casos (durante el embarazo o a posteriori del nacimiento) se enfocan en la salud infantil, articulándose con el Plan Nacer y Programa Sumar en el caso de las asignaciones "para protección social" (a efecto de contralor del 
destino de la inversión estatal). Si bien la cobertura se ha ampliado en los últimos años llegando a cada vez más beneficiarias, los montos de la asignación (variables en función de zonas geográficas predeterminadas) resultan a todas luces insuficientes en relación a los costos materiales de la crianza, y si bien está prevista su movilidad (Ley 27.160) con frecuencia semestral (Ley 26.417) el porcentaje de su actualización resulta insignificante $(6,68 \%$ a septiembre del 2018) en relación al incremento del costo de vida derivado del proceso inflacionario en nuestro país. Por otro lado, los montos máximos de ingreso familiar (IGF) establecidos para la percepción del beneficio (relevados a septiembre del 2018) se complementan con topes máximos de ingresos de cada integrante del grupo familiar, (por ejemplo, para un IGF de \$83.917 se fija un ingreso máximo para cada integrante de \$41.959) en función de lo cual se establece un límite diferencial para el acceso al beneficio para las familias monoparentales; ello reviste interés por cuanto los estudios indican que la mayoría de los embarazos adolescentes desembocan en ese tipo de organización familiar.

\begin{tabular}{|c|c|c|}
\hline Acción & Año & Presupuesto \\
\hline \multirow[t]{5}{*}{$\begin{array}{l}\text { Programa Nacional de } \\
\text { Educación Sexual Integral } \\
\text { (ESI) }\end{array}$} & 2018 & $\begin{array}{l}\$ 22 \text { millones (destinados a capacitaciones } \\
\text { específicas de } 2.000 \text { docentes en } 10 \\
\text { provincias) Se asiste financieramente a } \\
\text { solicitud. Las capacitaciones nacionales son } \\
\text { virtuales }\end{array}$ \\
\hline & 2017 & $\$ 43.211 .156$ \\
\hline & 2016 & $\$ 27.662 .623$ \\
\hline & 2015 & $\$ 55.755 .738$ \\
\hline & 2014 & $\$ 30.811 .868$ \\
\hline \multirow[t]{7}{*}{$\begin{array}{l}\text { Programa Nacional de } \\
\text { Salud Sexual y Procreación } \\
\text { Responsable (PNSSyPR) }\end{array}$} & a junio 2018 & $\begin{array}{l}\text { Crédito inicial } \$ 232.279 .489 \text { que asciende a } \\
\$ 373,6 \text { millones. El incremento del } 55 \% \text { se } \\
\text { destina a plan ENIA en compra de } \\
\text { anticonceptivos }\end{array}$ \\
\hline & 2018 & $\$ 372,76$ (millones) \\
\hline & 2017 & $\$ 224,14$ (millones) \\
\hline & 2016 & $\$ 173,53$ (millones) \\
\hline & 2015 & $\$ 150,61$ (millones) \\
\hline & 2014 & $\$ 802,96$. (millones) \\
\hline & 2013 & $\begin{array}{l}\$ 66.119 .315 \text { (estimado) } \\
(\$ 25.751 .900 \text { tratamientos anticonceptivos y } \\
\text { otros insumos) }\end{array}$ \\
\hline \multirow[t]{2}{*}{ Plan ENIA } & 2018 & $\$ 182$ millones \\
\hline & 2017 & $\$ 127.753 .718$ promedio \\
\hline $\begin{array}{l}\text { "El embarazo no } \\
\text { intencional en la } \\
\text { adolescencia: su abordaje } \\
\text { desde la escuela } \\
\text { secundaria" }\end{array}$ & 2017 & $\$ 8.000 .000$ \\
\hline Plan Nacer & 2004-2012 & USD: S435.8 millones \\
\hline
\end{tabular}


Por último, la inclusión y el análisis de los montos de las inversiones en algunos de los programas relativos a la salud sexual y la procreación responsable se consideró necesaria en razón de que toda política pública supone la asignación de fondos, condición de su ejecución $\mathrm{y}$, en la medida en que la temática se enmarca en el ejercicio de derechos debiera tener en cuenta que "el hecho de tomar conciencia de los costos no tiene por qué reducir nuestro compromiso con la protección de los derechos básicos. [...] preguntarse sobre el costo de los derechos no es lo mismo que preguntar cuánto valen los derechos (Holmes y Sunstein, 2015, pág 47). Tematizar entonces las políticas de derechos requiere ineludiblemente el análisis de los presupuestos asignados, dados que todos los derechos son costosos porque todos presuponen una maquinaria eficaz de supervisión, pagada por los contribuyentes para monitorear y controlar.

El "Manual para la evaluación de políticas públicas" (2016) establece que junto al aprendizaje y la mejora continua, uno de los objetivos de la evaluación es la "rendición de cuentas" (pág. 14), dado que las evaluaciones permiten estimar la medida en que una intervención está logrando los efectos e impactos deseados sobre una población meta y generan evidencia relacionada a la aplicación (uso) de los recursos públicos. El Estado debe entonces rendir cuentas del uso de los fondos cuya administración le es delegada por la ciudadanía no sólo en términos de aplicarlos a los fines previstos sino también del "buen uso" en relación a la solución o, por lo menos, a la mejora de la situación inicial.

Como puede verse en el cuadro, las inversiones son cuantiosas y los datos se mantienen sin variación. Consideramos importante señalar que en esta etapa inicial de la investigación nos encontramos con las dificultades que implican por un lado, encontrar el dato a partir del rastreo y chequeo a través de múltiples fuentes de información, las dificultades en la comprensión de los códigos y nomenclaturas propias del campo de la administración pública, la distinción entre lo asignado y lo efectivamente devengado, a lo que se añade la consideración de las múltiples dependencias que intervienen sobre este tema asignando presupuesto diferencial en la medida en que se suman a las pretensiones que establece una ley nacional.

Gestionar políticas públicas requiere evaluarlas y asumir responsabilidades por los resultados. Los derechos no sólo tienen un precio/presupuesto, sino que debe analizarse cómo se administran y quiénes se terminan beneficiando. Como señalan algunos autores, el estudio de la administración de los presupuestos parece ser un campo, si no abandonado, poco observado por la intelectualidad progresista. Tarea, que el campo académico debería asumir, si no es a costa de falsear la tan mentada criticidad del pensamiento.

\subsection{Los datos según la perspectivas de los/as actores.}

Uno de los objetivos de la investigación tuvo por intencionalidad "Analizar las políticas públicas de salud sexual y reproductiva desde las perspectivas de las/os actores/as" razón por lo cual se realizaron las siguientes actividades:

- Un Taller en el CIC Virgen del Valle denominado "El embarazo adolescente: un estado de la cuestión", implementado en la Semana de la ciencia. En dicho taller se presentaron los primeros resultados respecto a los datos construidos sobre la tasa de fecundidad y el relevamiento de los planes y programas con el objetivo de conocer si los/as adolescentes se percibían sujetos de las políticas públicas destinadas a ellos/as. Asistieron estudiantes de la escuela secundaria Lugones (barrio Gob. Gregores), del colegio $\mathrm{N}^{\circ} 6$ (barrio 2 de abril) y colegio Espínola (privado confesional) acompañados por adultos responsables de cada institución (preceptoras, profesoras, y rector según el caso) y adultos/as de proyecto "Crecer en comunidad" (programa municipal que atiende adolescentes de 13 a 18 en situación de 
"vulnerabilidad"), del "Pequeño hogar de niños" (atiende niños/as y adolescentes judicializados y es de dependencia municipal) y equipo de orientación del colegio $\mathrm{N}^{\circ} 22$ (barrio Güemes). La decisión de realizarlo en el CIC respondió al criterio de acercarnos al territorio (rasgo central de la convocatoria de la semana de la ciencia)aunque nos encontramos con muchísimas dificultades en términos operativos y de difusión puesto que parte de los profesoras involucradas en la coordinación de dichas actividades objetaron la difusión por parte del MDS-CIC. En concreto, tanto el diseño de afiches como la difusión, provisión de audio, y espacio fueron provistos por MDS y la universidad aportó con un cañón que pudimos retirarlo.

- Un conversatorio denominado "Tejiendo diálogos entre jóvenes y adultos" (inicial a la jornada "Juventudes, Políticas Públicas y Desigualdad Social") el que pudo ser realizado por el financiamiento obtenido en la convocatoria a Proyectos Especiales de la sede UACO y cuya temática nace del taller mencionado ut supra. Previo al mismo realizamos charlas en escuelas secundarias y oratorio Lapeyrade que trabaja para y con niños/as y adolescentes (tiene un comedor que ofrece cena y brinda talleres de formación), extendiendo la convocatoria al Centro de Estudiantes de la UNPA y madres y padres usuarios del Centro Jardín materno - infantil de la institución. Esta actividad fue declarada de interés provincial (Declaración 024/2019 del Poder Legislativo de la Provincia de Santa Cruz).

- Entrevistas a asistentes sociales, operadoras y a la Directora Regional - MDS de zona norte, responsable del CIC "Virgen del Valle" con el objetivo de conocer planes y programas que se implementan en territorio y las percepciones respecto de la temática. Es de remarcar que el cambio al diseño inicial de conversatorio (implementarlo en el CIC) se debió a un cambio intempestivo en la gestión política razón por la cual cayeron los acuerdos previos de actividades y por la temporalidad del proyecto -1 año- no contamos con tiempo suficiente para renegociaciones posibles. De hecho, se hizo el intento, pero fuimos derivadas a nuevos trámites administrativos y a otros CIC.

Del análisis y categorizaciones realizadas del material cualitativo se presenta a continuación los resultados ordenados según la perspectiva de los adolescentes y jóvenes en tanto receptores y de los adultos en tanto gestores y agentes que intervienen en el desarrollo de políticas públicas vinculadas a la salud sexual y salud reproductiva.

\subsubsection{Las voces de los/as adolescentes y jóvenes}

En el taller realizado en el CIC, luego de la presentación de los datos relativos a tasa de fecundidad y relevamiento de planes y programas, se procedió a trabajar en grupos (ocho grupos de adolescentes) a partir de cuatro interrogantes, como disparadores del diálogo, cuyas respuestas se socializaron posteriormente. ¿Con qué respuestas nos encontramos y qué análisis podemos hacer?

En primer lugar, sobre el conocimiento de los planes y programas nos encontramos con un importante desconocimiento sobre los mismos. "Nosotros particularmente, no sabíamos nada de los planes" "no sabíamos de que había tantos, o de la cantidad de plata que los mismo generan". De los grupos que manifestaron conocer planes vigentes, el 50\% de los grupos manifestó conocer la asignación por hijo, y uno solo expresó conocer el Plan Nacer. Sólo uno de los grupos indicó conocer el plan de educación sexual integral (ESI), y uno hizo referencia a la distribución gratuita de preservativos. Un solo grupo expresó no tener ningún conocimiento de los planes relativos a salud sexual. Resulta interesante la disociación entre haber recibido o participado de clases o charlas sobre educación sexual y el conocimiento del programa "ESI". Vale preguntarse por las formas en que se presentan las acciones del programa a los/as adolescentes pues pareciera que su abordaje es desgajado de la tematización 
y trama en la que se asienta el programa. Esto porque hay una diferencia sustantiva en presentar el "problema" anclado en la trama social y política en que se produce y otra, bien distinta, presentarlo como un contenido descontextualizado (tema muy debatido en educación pues esa descontextualización obtura el poner en cuestión el pensamiento hegemónico como condición de reproducción).

En segundo lugar, sobre lo que les "llega" de los planes sólo dos grupos manifestaron haber participado de charlas de educación sexual y colocación de preservativos. Sobre este punto podemos considerar que -según fuentes relevadas- Santa Cruz se suma tardíamente o escasamente pues la legislatura adhiere en marzo de 2009 y en el 2014 participa de las capacitaciones presenciales. No tenemos información de la participación en instancias virtuales de formación ni de la recepción -sea desde MDS o MSal- de los materiales, cartillas de difusión aun cuando se informa que en el 2009 se distribuyeron materiales de difusión en todas las jurisdicciones. Y respecto de la campaña de capacitación docente "Es parte de la vida, es parte de la escuela", dependiente del programa ESI, que se inició en el 2012 (primera etapa), la provincia participó en 2016 - 2017. Si cruzamos las opiniones de los/as estudiantes con el relevamiento de los planes y programas nos encontramos con que aun cuando hay diferencias en las formas de intervención entre los dos últimos gobiernos, la provincia -pese a haber creado en el 2010 el Programa Provincial para el ejercicio de la Salud Sexual Integral y la Procreación Responsable asignando incluso, como se señaló en el apartado 3, presupuestono ha tomado iniciativa propia respecto de la temática, por lo menos, hasta el momento del relevamiento en este proyecto. Mientras que en el kirchnerismo encontramos que en las normativas e informes se establece distribución de cartillas y materiales para todas las jurisdicciones en el área educativa, en la gestión macrista las intervenciones fueron segmentadas y organizadas en el tiempo (en la primera etapa se trabaja con las zonas con los más altos índices de la tasa de fecundidad y en la segunda etapa se suman las restantes provincias). Esta realidad bien puede vincularse con lo señalado en el apartado 4.1 respecto de los escasos resultados de las políticas públicas y una tasa que se resiste a descender.

En tercer lugar sobre la valoración que hacen respecto de los planes que no conocían, en términos generales los/as adolescentes valoran positivamente que el Estado intervenga en esta temática sea por las charlas, la entrega de preservativos, asignación monetaria y planifique acciones destinadas a ellos/as. "De los planes que no conocíamos nos resultan interesantes porque traen muchos beneficios que antes no se habían visto que son para evitar embarazos o para ayudar a las mujeres embarazadas"; "Valorizamos que el estado intente o busque brindar ayuda con preservativos e información para el cuidado de la salud"; "Nos parece bien que esos planes ayuden a informar a las personas, porque en muchas situaciones hay muchas personas que no saben o no se informan sobre el tema”. Respecto de estas valoraciones nos parece que sería interesante indagar por un lado, el tipo de demanda que se hace al estado y por el otro, las particularidades de la adolescencia actual en referencia al mundo de los/as adultos/s que las rodea y sus formas de vinculación. ¿Qué supliría el estado en términos de vinculación intergeneracional?

En cuarto lugar, sobre situaciones ligadas al embarazo adolescente que las políticas públicas no abordan, reportan mayoritariamente temáticas o problemas que son de orden estructural y que remiten a las condiciones de desigualdad social y polarización social: "faltan actividades recreativas", "qué otra cosa tengo para hacer en dos cuadras?" (haciendo alusión a los espacios públicos disponibles); "queda sin resolver la finalización de los estudios, no tener tiempo propio, la vivienda y demás, que no pueden mantener a sus bebes". "Los menores de edad no pueden obtener un trabajo, por lo tanto no es posible solventar los gastos de una familia". Resulta llamativo que uno de los grupos hiciera referencia a las limitaciones de los planes en cuanto a su implementación y resultados pues señalan "puede quedar sin resolver, es la falta de información sobre la educación sexual. Los planes fallan al no llegar la ESI 
suficiente, en la calidad de los preservativos y a veces, en su vencimiento, en no llegar a sectores vulnerables y no cubrir a los colegios privados." Esta afirmación bien podría entenderse como una evaluación de lo que perciben sobre los planes y programas en tanto receptoras/es de los mismos. Otra afirmación que nos resultó aún más llamativa refiere a la inseguridad: "otra situación sin resolver es la inseguridad en la Argentina, que no te garantiza que puedas salir de tu casa sin temor a que te pase nada", puesto que revierte los discursos donde los/as adolescentes son los generadores de situaciones de violencia en la sociedad. A lo que podemos preguntarnos, si ellos/as padecen violencia, qué planes o programas responden a esta necesidad y si el problema es "visto" por los responsables de diseñar políticas públicas. Por último, resulta significativa la afirmación de uno de los grupos, que a la consideración de aspectos estructurales, añade: "Es dificil hacerse cargo de un niño sin experiencia y con una corta edad." Esto nos remite a la discusión sobre el lugar y la concepción sobre los adolescentes por parte del mundo adulto. Otro diálogo interesante resultó cuando uno de los adolescentes nos señaló "en mi primera relación con mi novia usé preservativo. Pero después no lo usé más” y ante la pregunta "¿por qué no lo usaste más? respondió "porque después ya estábamos seguros, nos sentimos seguros", "estaba seguro con ella”. Lo interesante es que la referencia a la seguridad gira en orden al vínculo de pareja y no a la posibilidad de embarazo. A riesgo de ser reiterativas, nuevamente la información no es la variable determinante.

De la segunda actividad realizada con adolescentes y jóvenes, resulta interesante destacar que, en la medida en que los/as adultas/os hacemos silencio y voluntariamente hacemos un esfuerzo por escuchar y no llenar de palabras el espacio, los/as jóvenes pueden hacer escuchar su voz y en ella, expresar los malestares y sufrimientos que habitan su vida. También comprobamos que disponiendo lugares y tiempos que habiliten la expresión y el tratamiento colectivo del malestar social, los/as jóvenes (y los/as no tan jóvenes) se permiten poner en juego el cuerpo y las emociones y entonces, el llorar no resultó un acto individual sino que el llanto mismo cuando es escuchado y sostenido solidariamente, habilita a que las palabras compartidas ayuden a la construcción de un nosotros/as.

De esas voces adolescentes y/o juveniles, surgen interpelaciones a los/as adultos en torno a:

- El embarazo adolescente es un ¿problema? Las preguntas o afirmaciones que realizaran “¿para quién es un problema?” y "ninguna chica quiere quedar embarazada” o "¿quién quiere ser madre a los 16 años?", mostraron discrepancias entre las formas que se percibe el fenómeno entre los jóvenes. Cabe consignar que el debate en torno a si el embarazo adolescente es - o no - un problema, se encuentra atravesado por la disputa contemporánea en nuestro país en torno a la despenalización del aborto. La forma en que se piensa y conceptualiza la situación de las jóvenes adolescentes respecto del embarazo no intencional (no intrínsecamente "problemático" o no deseado) determina tanto las formas de intervención como la direccionalidad y asignación de presupuesto y personal. Al partir de caracterizaciones o supuestos equívocos se concatenan una serie de acciones que tienen por resultado la no modificación de lo que se pretende cambiar, es decir, la perpetuación del fenómeno. Quizás sea pertinente la generación de líneas de investigación para precisar los conceptos que utilizamos (tanto académicos como gestores) a efectos de no anular la demanda y tomar las necesidades y perspectivas de las jóvenes para no caer en discursos y políticas que perjudican a los más pobres; esto implica el esfuerzo de la academia para la escucha y construcción de demandas calificadas.

- La escasez y/o ausencia de diálogo con adultos/as: "no nos escuchan” (expresión que se utilizó reiteradamente respecto de padres/madres, maestras/os y profesores/as) y, como señalaron en las charlas en colegios, "no nos escuchan y nos miran como a la generación perdida cuando los perdidos son ellos" Resulta llamativo que ante tantas acciones y capacitaciones para generar capacidades y lugares de diálogo con los/as estudiantes sobre la 
sexualidad y la procreación responsable, nos señalen tan directamente la falta de escucha cotidiana. Mucho más si consideramos lo sensible que es el tema y la puesta en juego de las propias sensibilidades cuando nos remitimos a la sexualidad.

- El valor de la educación para los sectores populares (la joven había sido receptora del proyecto crecer en comunidad) expresado en la frase "la educación me salvó" pero al mismo tiempo "estudié cuatro años, ahora no consigo trabajo y todos los años siguen habiendo más profesoras de nivel inicial... ¿para qué estudié?” Por un lado es cada vez más necesario repensar la vinculación educación-empleo y por otro, la afectación del desempleo y el trabajo precario en los sectores más jóvenes.

- En una de las charlas previas al conversatorio, en una escuela privada, señalaron "viven trabajando y después nos regalan un Iphone, como si eso nos hiciera felices". El fenómeno de no diálogo parece una cuestión que atraviesa las clases sociales y asume sus diferentes formas de expresión, pero pareciera que alude o nos referencia a un problema intergeneracional. ¿Cómo se expresa y qué efectos produce la mercantilización de los vínculos afectivos y la fragmentación en la vida familiar?

De lo explicitado anteriormente, claramente podemos ver que los/as receptores/as no sólo no se ven a sí mismos como destinatarios de los programas sino que los que los conocen, los conocen porque ya ha vivido un embarazo o ha ocurrido en sus vínculos cercanos. La falta de información resulta paradojal si tomamos en cuenta que es el argumento sobre el que se asientan todas las acciones. Entonces la pregunta que nos seguimos haciendo y que amerita estudios más prolongados, es ¿qué se demanda con la información? ¿es información o diálogo y transmisión de experiencia? Por otro lado, ¿qué tan válido es pensar el fenómeno del embarazo adolescente, e intervenir sobre él, considerando la sexualidad aislada del resto de las circunstancias vitales que atraviesan los/as adolescentes?

\subsubsection{Las voces de los adultos/as que gestionan.}

En el taller realizado en el CIC, los dos grupos de adultos refieren a tener escaso conocimiento de los planes y programas "En nuestro grupo se conoce muy poco de los planes vigentes"; "Conocemos de algunos planes a nivel, provincial, municipal y estatal de remuneración económica” así como no recibir información o acción de planes oficiales "Como institución educativa no nos llegan capacitaciones ni información como para convertirnos en agentes multiplicadores", "No hay difusión ni asesoramiento de lo abarcativo en cada plan". Este señalamiento coincide con lo analizado en el apartado 4.2 respecto del ingreso tardío de la provincia a considerar la temática.

Respecto de las situaciones ligadas al embarazo adolescente que las políticas públicas no abordan, resulta significativo que hayan consignado -al igual que las/os adolescentes- las limitaciones de los planes en cuanto a su implementación y resultados pues señalan: igualdad en información sexual, pedir más charlas sobre las políticas de salud, falta de información sexual y del cuidado de la pareja, falta de contención a las adolescentes embarazadas, charlas de concientización, políticas de salud para evitar el abuso obstétrico, charlas para madres de hijos adolescentes. Al igual que los jóvenes señalan problemas de orden estructural -“vulnerabilidad social"- aunque no definen con precisión los aspectos que deberían ser abordados a ese respecto. Una de las expresiones significativas resultó "Consideramos que cada región tiene sus particularidades, pero Santa Cruz consideramos que el problema no es por desinformación." En este punto vale señalar que en la puesta en común se generó un intercambio entre jóvenes y adultos respecto del supuesto de que el embarazo se produce por falta de información. Los/as adultos ponían el énfasis en el acceso a las tecnologías como fuente de información de los sistemas anticonceptivos comparándolos con los recursos disponibles en la generación pasada. Lo llamativo es que esta percepción de los adultos 
también fue expresada en las distintas entrevistas que nos realizaron en los distintos medios de comunicación al momento de la difusión de las actividades. De aquí que presumimos que la asociación información-embarazo adolescente amerita, como señalamos en el apartado previo, analizar si hablamos de una demanda de información o de diálogo con adultos o transmisión de experiencia en un tema que si bien, en sus trazos gruesos puede generalizarse, no puede establecerse universales válidos para todos/as.

Respecto de los/as entrevistas a adultos gestores de políticas públicas en el CIC- MAS y en función de la categorización realizada, podemos señalar que:

1. Para el abordaje de la temática del embarazo adolescente la escuela pública aparece como un lugar deseable desde donde conectarse con las/os adolescentes, aunque el diálogo entre estudiantes y agentes sanitarios es a iniciativa individual y no se deriva de acuerdos institucionales o estratégicos "se cruzan las chicas del colegio secundario y las agentes sanitarias están así, como muy predispuestas y ellas también se han cruzado para tratar este tema directamente en las aulas". Al mismo tiempo señala "no es tan fácil ingresar a los establecimientos educativos como para poder que, haya una fluidez en ese trabajo" Resulta interesante el nexo con la escuela especial pues nos advierte de la atención en las personas con discapacidades cuando hablamos de educación sexual reproductiva: "hay ciertas cuestiones que los chicos con cierta discapacidad cuando llegan a cierta edad, no por una cuestión de ellos mismos, sino por una cuestión de la familia o de los padres no saben cómo encararlo, no saben cómo manejarlo, entonces, la idea es empezar con charlas al respecto de todo lo que es educación sexual o reproductiva y de cómo trabajarlo principalmente, con los padres y después con los propios alumnos de las escuelas especiales." La observación que realiza sobre los padres responde a una situación en que los padres pretendían operar a la joven y por acciones de agentes sanitarios y CIC definieron el uso del DIU y el seguimiento (control) de la joven. El CIC amplía entonces, su servicio al articularse con el área de estimulación temprana de la escuela especial, siendo el primero el derivador de los "casos" vía intervención del/la pediatra. Se propone como la organización de una red.

El cruce o yuxtaposición de CIC municipales y provinciales se contrapone a las estrategias de gestión que definiera el gobierno nacional-ministerio de desarrollo, por lo menos, al 2010; "dentro de esa misma jurisdicción hay CIC municipales que abarcan y que cubren la misma jurisdicción pero provinciales, ya es como un cruce”. Lo mismo sucede con la vinculación con el hospital, "por ahi el hospital si hace un trabajo cuando sale a hacer campañas de prevención de VIH SIDA, [...], el hospital sí, hace trabajo tanto con los CIC provinciales como con los CIC municipales, pero ya, con personal del hospital." Por otro lado, el CIC cuenta con un CDI, respecto del cual expresa: "tenemos el CDI, el centro de desarrollo infantil, dentro de acá del CIC, entonces tenemos otro tipo, con otras áreas, estamos más relacionadas como por ejemplo con la secretaría de la niñez que depende de la municipalidad", "tenemos muchos casos que son derivados de la secretaría de la niñez, por distintas cuestiones... problemáticas familiares"; "Entre CIC y CIC hay algunos trabajos, hay algunas áreas que se trabajan en conjunto, pero no son las de salud. Lo que se aprecia es un cruce de actividades más que una articulación estratégica planificada.

Sobre la población adolescente se destaca la magnitud de la población adolescente en la localidad "la cantidad de adolescentes que tiene Caleta, que es Impresionante" y la referencia a la información suponiendo que el acceso a las nuevas tecnologías debería garantizarla "muchas veces uno supone de que como las adolescentes manejan y tienen acceso a información, como que están informadas. Y se han llevado la sorpresa de que muchas veces no están informadas"; "como que sí, la información la tienen a mano, pero a veces no la aplican bien y no la tienen muy clara que digamos" desplazándose el problema a las capacidades e iniciativas individuales. Respecto de la repitencia del embarazo señala que "una vez te podes descuidar, pero, ya cuando tienen por ejemplo 20 años y tienen tres chicos 
o dieciocho y tienen tres chicos, algo está fallando." con lo cual el "descuido" nos lleva necesariamente a pensar en términos de responsabilidad lo que se fortalece en el señalamiento de las edades. Esta argumentación se fortalece cuando nos señala "muchas veces, se hacen cargo de los chicos, de los menores, la abuela [...] yo no sé si es por una falta de, no sabría decirte si es por desinterés, si es por despreocupación, entonces, también por eso, está focalizado el tema de trabajar con la mamá", donde la falta de responsabilidad se prolonga en las actividades de crianza del hijo. Resulta interesante que pese a intentar relativizar las responsabilidades y manifestar cierto desconocimiento, el trabajo social del CIC vuelve a centrarse en la madre y no en otras variables que configuran el fenómeno.

Sobre las acciones específicas del CIC sobre salud sexual y reproductiva las mismas parecen desplegarse desde la difusión en eventos "una de las cosas que hacemos es cuando hay jornadas, de cualquier otro tema, [...] lo que se hace desde el ministerio de desarrollo, es tener un stand con este tipo de información", a lo que agrega "tratamos en cada una de las actividades que se hace que haya un stand en dónde están las agentes sanitarias informando y entregando documentación, entregado preservativos y capacitando a todo el que se acerque [...]Eso tratamos de hacerlo siempre", donde puede verse coherencia con los lineamientos posibles de ser discutidos como venimos señalando - que sustentan las políticas sociales del MDS.

En la entrevista, pudimos confirmar la inexistencia de programas específicos referidas a sexualidad/reproductiva lo que podría ser razonable pues el programa nacional está en dependencia de Ministerio de salud aunque el Plan Estratégico de salud de Santa Cruz estipula articulaciones con los CIC "Salvo las capacitaciones y la prevención y las charlas de asesoramiento sobre los distintos métodos anticonceptivos, no [hay] . En algunos casos hay seguimientos pero ya en la embarazada."; “Cuando son embarazos adolescentes, hay como un seguimiento sobre si recibe la medicación [...] si se alimenta bien. o sea que, retire la caja por ejemplo de leche del plan materno infantil., Sí se las provee de lo que es el Hierro, el ácido fólico, hay un seguimiento". Como puede apreciarse las actividades se despliegan sobre la madre en relación a la salud del bebé quedando por fuera otras variables estructurantes que la política social no logra o no puede resolver.

Sobre la caracterización sobre el Personal del CIC, en primer lugar la directora refiere insuficiencia del personal en relación al territorio que comprenden los CIC provinciales, "por la población que es, yo creo que tendría que haber más. Por la población que tiene Caleta y más en lo que es la cantidad de adolescentes que tiene Caleta". En segundo lugar, respecto a las formas de intervención, "muchas veces es iniciativa de ellas, sí, a ver, las agentes sanitarias principalmente las del CIC San Cayetano que son las que más territorio tienen” "es también por una preocupación de ellas, en donde han planteado salir a hacer territorio y salir a los barrios". Se contrapone así la visión de intervenir en terreno con las estrategias de gestión social que dieron origen o explicaron la constitución de los CIC, reemplazando las iniciativas individuales a las acciones sistémicas o de gestión pública.

Sobre la estructura de los CIC, nos señala la existencia de tres centros provinciales, "el CIC Virgen del Valle, el CIC Gobernador Gregores, y él CIC San Cayetano. Esos son los tres CIC que dependen de la provincia, en Caleta", contando los dos últimos con centros de salud incorporados lo que les otorga un perfil diferenciado: "el Gregores siempre fue un CIC en donde el fuerte era la parte de salud. Y el San Cayetano exactamente lo mismo. Acá, en el caso de este, como el área de salud está como aparte, el Virgen del Valle es un CIC donde se atienden más cuestiones sociales".

Y respecto de la modalidad de gestión "Aunque cada uno de los CIC es independiente. Cada uno de los CIC tiene su jurisdicción. Lo que hay es una dirección provincial que es la que supervisa a los tres CIC. Y en todos los CIC que hay en la provincia se maneja las mismas, la misma forma de trabajo, es más, se manejan los mismos horarios, los mismos programas, 
en lo que es social es la misma forma de pedido de asistencia o de ayudas financieras, es exactamente igual." Si bien se refiere a la autonomía de cada CIC, la homogeneidad en la gestión e implementación de los programas (aun cuando se gestiona presuponiendo problemáticas distintas en el territorio) da cuenta o bien de cierta verticalidad desde la gestión central que barre con el criterio de territorialidad o bien del escaso ejercicio autónomo y propositivo de los CIC.

\section{CONSIDERACIONES FINALES: PLANTEANDO DEBATES EN TORNO A LOS RESULTADOS.}

Como se documenta en los estudios previos y se verifica en las series históricas construidas, nuestro país representa una "anomalía" a nivel regional. Así, pese al descenso general y progresivo en la tasa de fecundidad adolescente durante la segunda mitad del siglo XX, en nuestro país el nivel más bajo se registró en el año 2003 (57,5 por mil, considerando la adolescencia tardía) momento a partir del cual -pese a ser el año en que se inician las políticas públicas ligadas a la salud sexual, que contemplan entre sus objetivos la prevención del embarazo adolescente- presenta un crecimiento sostenido llegando al 69,6 por mil en el 2011, situándose así con la tasa más alta de los países del Cono Sur. Esta situación per se implica la necesidad de repensar el diseño y la implementación de las políticas públicas dirigidas a la temática en cuestión. Evidentemente la investigación se torna necesaria no sólo en lo que respecta a lo que sucede a nivel nacional sino especialmente por la dinámica oscilatoria de la evolución histórica del fenómeno en la provincia de Santa Cruz, tal como lo hemos explicitado en el apartado 4.1.

A ese respecto, y para dimensionar la complejidad del tema sería importante someter a revisión la construcción del dato en torno a la tasa de fecundidad vs razón de embarazo, que daría cuenta de manera más acabada del fenómeno que se pretende "medir" y sobre el cual intervenir. Conexo a este problema metodológico debemos considerar cómo se registran, se halla en disponibilidad y circulan los datos para el trabajo en territorio en la implementación de los programas, cuya falta de sistematización puede conllevar a intervenciones sin diagnóstico previo.

La complejidad del diseño y ministerios intervinientes relevados en el apartado de los planes se expresa en las entrevistas realizadas identificando cierta yuxtaposición y desarticulación, la cual se contrapone con las estrategias de gestión definidas en la constitución de los CIC . En este caso pudimos observar una sumatoria de acciones del orden municipal, provincial y nacional descompasadas pero que al mismo tiempo da cuenta de todo el esfuerzo y presupuesto estatal, sin resultados que modifiquen las condiciones que producen el fenómeno del embarazo adolescente (brecha esfuerzos / logros). La complejidad en estructuras burocráticas (y subestructuras) de la multiplicidad de ministerios intervinientes en la gestión se reduce dramáticamente cuando se debe intervenir en territorio con las/os adolescentes. Parece ser que ante cada problema la respuesta es la creación de una nueva estructura o de incorporar más personal al estado sin que medie una revisión del modelo de gestión en acción (actuar a demanda/inciativa individual vs acción planificada con participación popular/comunitaria).

Por otra parte, de los talleres con adolescentes pudimos constatar que pese a la cantidad de acciones o programas no pueden verse como sujetos de las políticas públicas. También los adultos expresaron no tener idea de tantos planes en marcha no pudiendo entonces ser "orientadores" o asesores de los jóvenes respecto de los espacios a los que podrían recurrir. Esta percepción coincide con el relevamiento jurídico respecto de la acción tardía de la provincia. 
Como se ha señalado el modo en que se piensa un "problema" y los factores que lo generan, determina las formas de intervención sobre él. En tal sentido, se puso en evidencia en los encuentros realizados la existencia de discrepancias en torno al carácter problemático del embarazo adolescente. El debate en torno a la intencionalidad del embarazo adolescente sólo puede entonces saldarse en análisis situados que consideren los significados subjetivos en articulación con las condiciones de la experiencia vital de las y los adolescentes y jóvenes. También en relación con los modos posibles de conceptualización del fenómeno y sus determinantes, corresponde señalar que el análisis tanto de la legislación como de los programas de acción vigentes indica a las claras su basamento en el supuesto de que las adolescentes se embarazan por falta de información. Nuestro primer acercamiento al diálogo con los/as jóvenes permite poner provisionalmente esa hipótesis en cuestión, por cuanto los/las adolescentes refieren conocer los métodos anticonceptivos e incluso usarlos. A similares conclusiones (brecha información/uso) llegan estudios académicos, así como la Encuesta de Salud Escolar. (A propósito de esa Encuesta cabe consignar la sorpresa que provoca que los resultados de la provincia de Santa Cruz estuvieran disponibles en la web del Center for disease control and prevention de Estados Unidos, mientras que no se encuentran en la web oficial de la provincia). Lo que resulta interesante es que los/elas adultos/as presuponen que por el acceso a la tecnología los/as adolescentes deberían contar con información y al mismo tiempo son esos adolescentes lo que reclaman es información. Ello nos permite pensar si hay un corrimiento de los adultos que "delegan" en la web la transmisión de la cultura al tiempo que apelan a la búsqueda autónoma (cual "cazador" de información) lo que implica dejar de lado la variabilidad de los sistemas de creencias y bagajes culturales con los cuales inicia la búsqueda y reinterpreta la información disponible. Reiteramos entonces que es dable preguntarse qué demandan cuando demandan información. Un último aspecto a destacar refiere a la fragmentación en la forma de concebir la problemática de los/as adolescentes. Si bien los lineamientos de los programas, así como la legislación de aplicación hace hincapié en la integralidad del abordaje, el ámbito de la sexualidad aparece desgajado de los aspectos sociales, económicos y culturales, especialmente generacionales. Todos los aspectos no contemplados en los planes y programas según las perspectivas de los/as receptores incluyen claramente a problemas que siguen sin resolverse como la finalización de estudios, posibilidades de empleo, solvencia económica y ocio. La tematización de la problemática de las/os adolescentes y jóvenes y la desigualdad que nos atraviesa como sociedad nos interpela como adultas/os y académicas/os en la escucha seria y responsable y exige desacomodarnos respecto de los ámbitos habituales o preferentes de intervención. Claro está que ello requiere reajustes metodológicos así como un esfuerzo mayor por parte de los/as investigadores/as para llegar o acceder realmente a los sectores sociales donde mayormente se expresa la situación. Respecto de ello es frecuente que se piense y se proponga a la escuela como lugar desde el que intervenir mientras que las propias investigaciones indican que, en una proporción importante, la salida del sistema educativo precede al embarazo. Vinculado a ello, el esquema de capacitación pensado para los/as docentes también requiere ser pensado pues por un lado el adulto oficia de intermediario y equiparable a la teoría del derrame en economía, se presupone un "derrame del conocimiento" que en algún momento llegará al adolescente y por el otro, el extraordinario presupuesto que implica dicho esquema de intervención sigue sin dar resultado. En el campo educativo, a más de veinte años de implementar capacitaciones sustentadas en esta visión neoliberal (el sujeto es el responsable del cambio sin modificar estructuras) y sin lograrse las mejoras esperadas ¿no obliga a pensar que el esquema de intervención debe cambiarse? Indudablemente no es suficiente sancionar la obligatoriedad de la educación sexual y proceder a capacitar a los/as adultas/os, sin considerar la coordenada temporal pues, la vida de los/as adolescentes sucede mientras tanto. 
Para un cierre que no deja de ser una apertura, el proceso investigativo realizado, y en ese marco, fundamentalmente, la articulación entre datos y el encuentro con las/os adolescentes y jóvenes, dio cuenta de la necesidad de escucha calificada a un sector que (paradójicamente, en una época de diversificación y proliferación de derechos, o casi de culto, a la niñez/ adolescencia) aparece como el más desprotegido, pese a las declamaciones e inversiones en las políticas públicas (para magros resultados). La experiencia del conversatorio nos posibilitó repensar nuestra práctica en dos sentidos. Por un lado el lugar y valor que le asignamos al cuerpo y a las emociones, (cosa que una encuesta no permite "capturar") junto con el orden de las palabras pues la puesta en juego de las experiencias de las/os jóvenes desde sus cuerpos, esto es decir, lágrimas, temblores y voces quebradas, nos obliga a pensar y repensar la escisión entre cuerpo-lenguaje, y poner en cuestión el lugar privilegiado y dominante del orden del discurso desencarnado de la vida misma. Por otro lado, respecto de la posición del investigador/a resulta más que necesario-por no decir urgente- repensar las bases ontológicas desde las cuales realizamos la escucha en el proceso de investigación. Se trata de recuperar aportes como los de Vasilachis (2009: 6) que nos llevan a considerar nuestras prácticas investigativas desde la igualdad ontológica y la desigualdad existencial lo que hace posible "que la voz del sujeto conocido no desaparezca detrás de la del sujeto cognoscente, o sea tergiversada como consecuencia de la necesidad de ser traducida de acuerdo con los códigos de las formas de conocer socialmente admitidas". Así, los aspectos éticos se tornan centrales, exigiéndonos el ejercicio constante de la reflexividad, en téminos de ser concientes de nuestra posición, en tanto en el acto investigativo, de manera inevitable, el/la investigador/a pone en juego su propio modo de ser y estar en el mundo.

Por último, un año intenso de investigación nos posibilitó dimensionar la vacancia en el abordaje de las juventudes en la región - en términos institucionales y no de los intereses / voluntades particulares de las/os investigadores/as - y hallar pistas para nuevas líneas de investigación así como para posibles ajustes a las políticas públicas estudiadas.-

\section{AGRADECIMIENTOS}

La realización de este estudio no hubiera sido posible sin la colaboración de los y las adolescentes y jóvenes que se acercaron y participaron de las instancias de encuentro y en particular del conversatorio popular. El equipo agradece también a quien fuera Directora del CIC Virgen del Valle, Sra. Paola Lamanuzzi y a las operadoras territoriales por su apertura y disposición al diálogo, así como a a los colegas cuya participación en la Jornada "Juventudes, desigualdad social y políticas públicas" enriqueció el debate y análisis de las temáticas que convocaron al encuentro.

\section{REFERENCIAS BIBLIOGRÁFICAS}

Amnistía Internacional. Embarazo en la adolescencia en la Argentina. Aportes al debate sobre derechos sexuales y reproductivos. https://doi.org/10.5867/medwave.2007.09.1252

BINSTOCK Georgina y Gogna Mónica (2015) La iniciación sexual entre mujeres de sectores vulnerables en cuatro provincias argentinas en Sexualidad, Salud y Sociedad Revista Latinoamericana ( $\mathrm{N}^{\mathrm{a}}$ 20. agosto 2015 - pp.113-140). https://doi.org/10.1590/19846487.sess.2015.20.09.a

CHAKIEL, Juan (2004) La dinámica demográfica en América Latina. CEPAL - CELADE, Santiago de Chile 
CLIMENT, G. I. (2009). Representaciones Sociales sobre el embarazo y el aborto en la adolescencia: perspectivas de las adolescentes embarazadas. Cuadernos FHyCS-UNJU (37), 221-242.

CONNING ARTHUR M, Simmons Alan B., et al El contexto social de cambio de la fecundidad en America Latina rural Aspectos metodológicos y resultados empíricos recuperado de https://repositorio.cepal.org/bitstream/handle/11362/32459/D08017.14-24_es.pdf?sequence=1\&isAllowed=y

Dirección de Estadísticas e Información de Salud, Ministerio de Salud de la Nación. (2015). Estadísticas vitales. Información básica. Argentina - 2015. Bs.As. https://doi.org/10.35537/10915/2490

HERNÁNDEZ SAMPIERI R., Fernández Collado C. y Baptista Lucio P.. (2006). Metodología de la investigación. México: McGraw-Hill.

HOLMES y Sunstein (2015), El costo de los derechos. Por qué la libertad depende de los impuestos, Argentina: Ed Siglo XXI.

INDEC. Encuesta Nacional sobre salud sexual y reproductiva. Buenos Aires.

Jefatura de Gabinete de Ministros (2016). Manual de base para la evaluación de políticas públicas -Segunda Edición-. Programa de Evaluación de Políticas Públicas, Jefatura de Gabinete de Ministros de la Nación y Ministerio de Modernización. Buenos Aires, Argentina. https://doi.org/10.5944/reppp.6.2016.16392

Ministerio de Salud de la Nación. (s.f.). Atlas federal de legislación sanitaria de la Republica Argentina. Recuperado el 23 de abril de 2018, de http://www.legisalud.gov.ar/atlas/categorias/salud_reproductiva.html\#sc https://doi.org/10.19137/cienvet-20161827

-- (2010). Boletín bimensual de salud sexual y reproductiva. Buenos Aires.

Ministerio de Salud, Dirección de Estadísticas e Información de salud. (Buenos Aires): Indicadores seleccionados de Salud para población de 10 a 19 años. Boletines Na 128 a 157. https://doi.org/10.1590/s0036-36342004000400010

Ministerio de Desarrollo Social y UNICEF (2013): Encuesta sobre Condiciones de Vida de Niñez y Adolescencia Principales resultados 2011-2012. Argentina

Ministerio de Salud, Santa Cruz (2011) Plan estratégico de salud 2011 - 2015

MUÑOZ AGUIRRE, N. A. (2011). El estudio exploratorio. Mi aproximación al mundo de la investigación cualitativa. Investigación y educación en enfermería , 29 (3), 492-499.

PANTELIDES Edith y Mario Silvia: Estimación de la magnitud del aborto inducido en Argentina, CEPAL, Notas de población Na 87

PANTELIDES Edith et al (2014): "Maternidad temprana en Argentina. Las madres menores de 15 años", CENEP

PERROTTA, G. V. (2006). Las adolescentes frente al embarazo. Memorias de las XIII Jornadas de Investigación. I Encuentro de investigadores en Psicología del Mercosur. (págs. 81-83). Bs As, UBA.

QUINTERO Rondón, et al. (2015, Febrero-Mayo). El embarazo a temprana edad, un análisis desde la perspectiva de madres adolescentes. Revista Virtual Universidad Católica del Norte (44), 223-236.

RODRÍGUEZ VIGNOLI, Jorge (2017) : Fecundidad no deseada entre las adolescentes latinoamericanas Un aumento que desafía la salud sexual y reproductiva y el ejercicio de derechos CEPAL (ONU), Santiago

SALUD, O. P. (2000). Recomendaciones para la atención integral de salud de los y las adolescentes con énfasis en salud sexual y reproductiva. Buenos Aires. https://doi.org/10.4067/s1726-569x2014000200007

UNESCO. (2017). Embarazo Precoz y no planificado y el sector de la educación. Revisión de la evidencia y recomendaciones. París: 
UNFPA (ONU) (2017): Prevención y reducción del embarazo no intencional en la población adolescente del cono sur Un marco estratégico subregional para mejorar la implementación de la política local (Argentina- Brasil- Chile - Paraguay - Uruguay). Asunción. https://doi.org/10.5354/0719-5281.2015.36781

UNICEF (2016): Situación de los y las adolescentes en la Argentina, Programa nacional de la Salud Integral en la Adolescencia. https://doi.org/10.14201/gredos.137327

UNICEF Argentina (2013): Situación del embarazo adolescente en Argentina. http://www.unicef.org.ar

UNICEF Argentina. (2017). Para cada adolescente una oportunidad. Posicionamiento sobre Adolescencia.

VAN TEIJLINGEN E, H. V. (2001): The importance of pilot studies. Soc Res Update.

VASILACHIS DE GIALDINO, I. (2006): Estrategias de investigación cualitativa, Gedisa. Barcelona.

VILLARREAL, M. T. (2009). Participación ciudadana y políticas públicas. Décimo Certamen de Ensayo Político. (https://www.ceenl.mx/educacion/certamen_ensayo/decimo/MariaTeresaVillarrealMar tinez.pdf) 


\section{ANEXO \\ Fuentes electrónicas consultadas para el relevamiento del apartado 4.2}

https://www.hcdn.gob.ar/prensa/noticias/2018/noticias_0705.html

https://www.hcdn.gob.ar/proyectos/proyecto.jsp?exp=5416-D-2018

https://www.argentina.gob.ar/desarrollosocial/ninezyadolescencia

https://www.argentina.gob.ar/educacion/esi/recursos/formaciondocente/audiovisuales

http://www.msal.gob.ar/index.php/component/bes_contenidos/?filter_problematica=9\&start=20

https://www.bancomundial.org/es/news/feature/2013/09/24/argentina-plan-nacer-resultados-concretospara-la-madre-nino

http://servicios.infoleg.gob.ar/infolegInternet/verVinculos.do;jsessionid=519F82BEADC66F9FC411D FDFB7D84681? modo=1\&id=121222

https://www.perfil.com/noticias/ciencia/lanzan-un-plan-para-prevenir-los-embarazos-

adolescentes.phtml

https://www.cippec.org/proyecto/proyecto-reduccion-del-embarazo-no-intencional-en-la-adolescencia/ https://www.argentina.gob.ar/educacion/esi/historia/embarazo-no-intencional

https://www.argentina.gob.ar/salud/saludsexual

http://www.salud.gob.ar/dels/entradas/salud-sexual-y-salud-reproductiva

http://www.salud.gob.ar/dels/tematicas/salud-sexual-y-reproductiva

http://www.telam.com.ar/notas/201709/205313-unicef-y-otras-organizaciones-lanzan-una-campana-

de-prevencion-del-embarazo-adolescente-no-planificado.html

https://chequeado.com/el-explicador/que-paso-con-la-inversion-para-reducir-embarazos-no-

intencionales-durante-la-gestion-de-cambiemos/

http://servicios.infoleg.gob.ar/infolegInternet/anexos/120000-124999/121222/norma.htm

https://docs.google.com/spreadsheets/d/11wSYaZYC15cxi2NSzHyAsR5WXhCRg6sEU793xwk-

FmM/edit\#gid=0

https://drive.google.com/file/d/0B6JXWBBzh14la295QzE0dzdXeTNZNG5WaGQ0T0tDWlZNVmZF

/view

https://drive.google.com/file/d/1lVvmSl-5r7HXO8q4dIW48Trk2jG5xqoe/view

https://docs.google.com/spreadsheets/d/11wSYaZYC15cxi2NSzHyAsR5WXhCRg6sEU793xwk-

FmM/edit\#gid=1158414094

https://docs.google.com/spreadsheets/d/11wSYaZYC15cxi2NSzHyAsR5WXhCRg6sEU793xwk-

FmM/edit\#gid=2116131790

https://www.argentina.gob.ar/sites/default/files/informe_111_-_hsn_-_27_de_junio.pdf

https://www.argentina.gob.ar/educacion/esi/historia/embarazo-no-intencional

https://www.argentina.gob.ar/planenia

https://www.hablemosdetodo.gob.ar/

https://www.tiempoar.com.ar/nota/como-hacer-para-cobrar-el-reintegro-del-100-en-la-compra-depreservativos-y-otros-anticonceptivos

https://www.justicia2020.gob.ar/wp-content/uploads/2018/12/Rendici\%C3\%B3n-de-cuentas-2018-

Justicia-2020.pdf

http://www.msal.gob.ar/images/stories/bes/graficos/0000001221cnt-boletin_virtual-10-

salud_integral_adolescencia.pdf

http://www.msal.gob.ar/images/stories/ryc/graficos/0000001073cnt-or-digital_adolescentes.pdf

http://www.msal.gob.ar/images/stories/bes/graficos/0000001282cnt-lineamientos.pdf

http://www.msal.gob.ar/images/stories/bes/graficos/0000001283cnt-insert.pdf

http://www.msal.gob.ar/images/stories/bes/graficos/0000001284cnt-0000001284cnt-guia-derechos-

2018.pdf

http://iah.salud.gob.ar/doc/Documento97.pdf

https://tbinternet.ohchr.org/Treaties/CEDAW/Shared\%20Documents/ARG/INT_CEDAW_ADR_AR G_19577_S.pdf

http://www.salud.gob.ar/dels/entradas/ley-nacional-de-salud-sexual-y-procreacion-responsable-no-

25673-y-decreto-reglamentario

https://www.argentina.gob.ar/educacion/esi/historia/embarazo-no-intencional 
http://www.bnm.me.gov.ar/giga1/normas/RCFE_322-17.pdf

http://www.msal.gob.ar/images/stories/ryc/graficos/0000000598cnt-experiencias-para-armar-baja.pdf http://compactonea.com.ar/index.php/noticias/view/17148

http://www.perfil.com/noticias/ciencia/lanzan-un-plan-para-prevenir-los-embarazos-

adolescentes.phtml

http://servicios.infoleg.gob.ar/infolegInternet/anexos/310000-314999/312783/norma.htm

https://www.anses.gob.ar/sites/default/files/cartilla/2018-09/CARTILLA\%20MONTOS.pdf

https://improvingphc.org/plan-nacerprograma-sumar-measurement-ensure-effective-universal-healthcoverage

https://www.argentina.gob.ar/educacion/esi/acerca/parte-vida-escuela

http://www.bnm.me.gov.ar/giga1/normas/RCFE_322-17.pdf

http://digesto.desarrollosocial.gob.ar/2019/search.php 